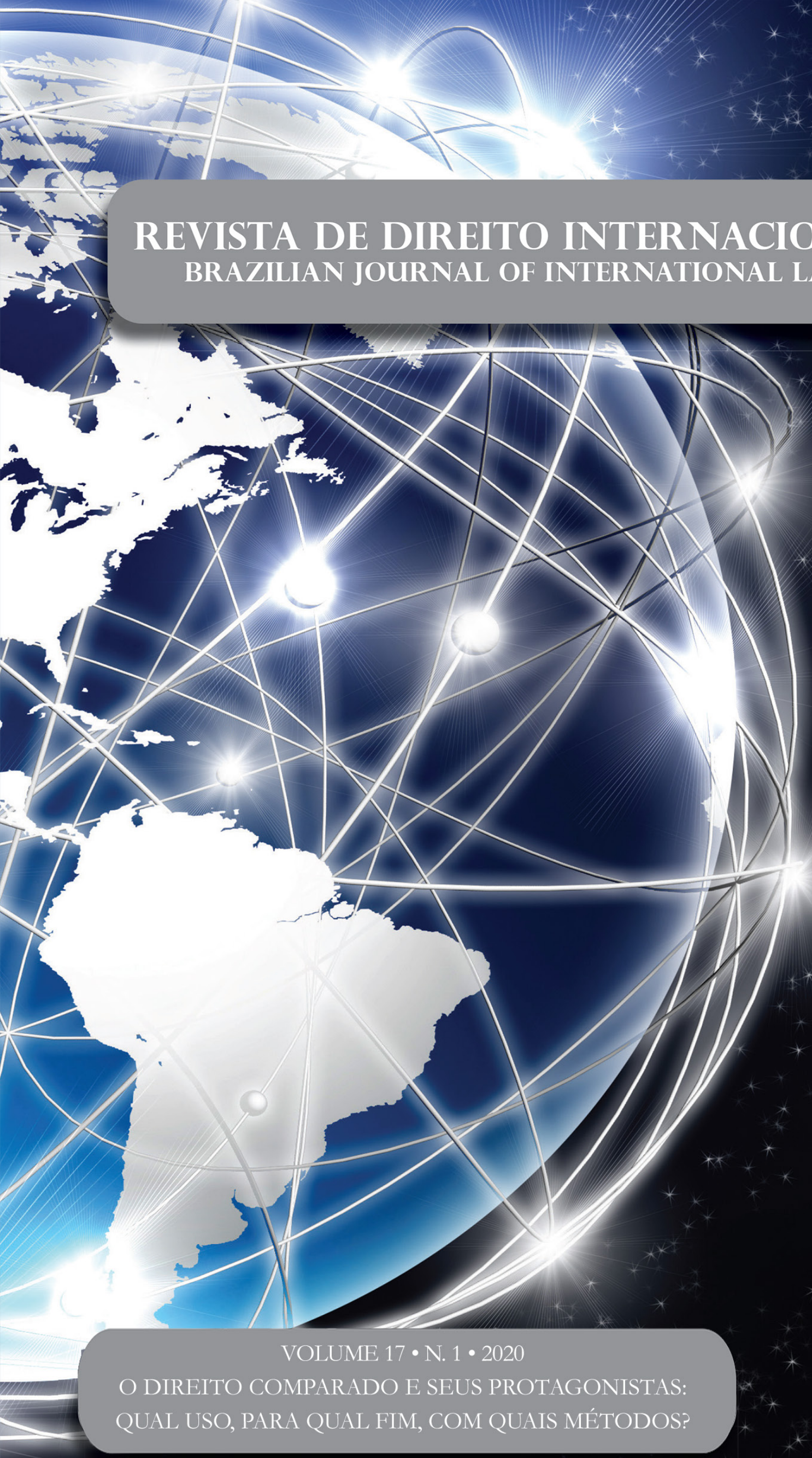

Comparando la cultura jurídica desde el derecho a la identidad cultural en Brasil y Chile

Comparing the Legal Culture from the Perspective of the Right to Cultural Identity in Brazil and Chile

Juan Jorge Faundes

Fabien Le Bonniec 
Parte I - O Direito comparado e seus Protagonistas: QuAL uso, PARA QUAL FIM, COM QUAIS MÉTODOS? .....................................................................1

EDITORIAL ............................................................................................................... 3

"Tudo o que precisamos fazer é ter certeza de que continuaremos conversando".............................. 3

Gustavo Cerqueira e Patrícia Perrone Campos Mello

Direito comparado E METOdologia $\quad$................................................... 6

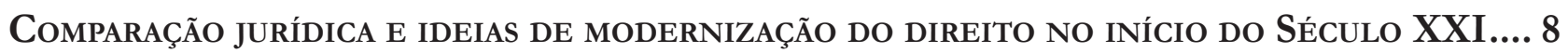
Gustavo Cerqueira

O DIREITO COMPARADO: ESFORÇO DE RESGATE HISTORIOGRÁFICO E DE PROBLEMAS METODOLÓGI$\cos$

Arnaldo Sampaio de Moraes Godoy e Gustavo Fereira Ribeiro

Direito Comparado e Política: Reflexões Necessárias .42

Raphael Carvalho de Vasconcelos e Deo Campos Dutra

Direito comparado no Brasil

L'originalité du Droit Brésilien et le Droit Comparé .57

Arnoldo Wald

LEI DA BOA RAZÃo E COMPARATISMO JURÍDICO NA DOUTRINA CIVILISTA BRASILEIRA DE 1850 A 1880

Alan Wruck Garcia Rangel

O STF EM REDE? QUANTO, COMO, COM QUE ENGAJAMENTO ARGUMENTATIVO O STF USA PRECEDENTES ESTRANGEIROS EM SUAS DECISÕES?

Patrícia Perrone Campos Mello e Felipe Meneses Graça 
Suprema Imprecisão: a metodologia em Direito Constitucional Comparado E as deficiênCias Em Seu uso pelo Supremo Tribunal Federal

Alonso Freire e Hugo Sauaia

Direitos comparados

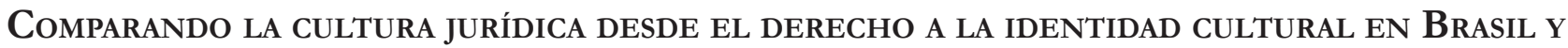

Chile 145 Juan Jorge Faundes e Fabien Le Bonniec

O Divino e o Racional no Direito: notas para um diálogo entre sistemas jurídicos 181 Salem Hikmat Nasser e José Garcez Ghirardi

Regulação do discurso de Ódio: análise comparada em países do Sul Global 196 Jane Reis Gonçalves Pereira, Renan Medeiros de Oliveira e Carolina Saud Coutinho

Parte II - Outros temas

LA OTRA CARA DE LA MONEDA: PROTECCIÓN CONSTITUCIONAL DE LA EMPRESA, EL EMPRENDIMIENTO Y LA LIBRE COMPETENCIA EN CHILE y COLOMBiA

Juan Pablo Díaz Fuenzalida e Juan Sebastián Villamil Rodríguez

The European Court of Human Rights Decision on there 'Burqa Ban'and the CritiCal analysis of the Pragmatic experimental logic 258 Flavianne Fernanda Bitencourt Nóbrega e George Browne Rego

Direitos humanos das deslocadas ambientais e os impactos da Usina de Belo Monte: da EXPLORAÇÃO AMAZÔNICA À SUBJUGAÇÃO FEMININA

Thais Silveira Pertille e Letícia Albuquerque

Solução de Controvérsias em Acordos de Investimento: as experiênCias do CPTPP, CETA E DOS ACFIs

Fábio Morosini, Vivian Daniele Rocha Gabriel e Anastacia Costa

50 anos dos “direitos da Criança” na Convenção Americana de Direitos Humanos: a HISTÓRIA DO ARTIGO 19 311

Sven Peterke e Paloma Leite Diniz Farias 
EMPRESAS E DIREITOS HUMANOS: COMPARTILHANDO VALOR E RESPONSABILIDADES .325 Melina Girardi Fachin

CONTEMPORARY RESPONSES TO BUSINESSES' NEGATIVE HUMAN RIGHTS IMPACT 341 Andres Felipe Lopez

Human Right to LABOR PROTECTION IN UKRAINE: CURRENT SITUATION AND THE PROSPECTS OF IMPLEMENTATION OF INTERNATIONAL RULES 363 Nina Daraganova

International Regulation and Global Governance: The EU influential Method IN TIMES OF NORMATIVITY CHANGE 373 Gabriela Hühne Porto, Paula Wojcikiewicz Almeida e Juliana Maia F. A. Netto

Tecnologias digitais e o comércio de bens E SERviços na OMC/Digital. 391 Umberto Celli Junior

Los fuertes hacen lo QUe PUeden: exponiendo los límites de la Corte Penal InternaCIONAL .406

Cristián D. González-Ruiz e Víctor M. Mijares

Human Rights, Humanitarian Law and State Power 418 Renata Nagamine e João Roriz

Regional integration in the South Pacific: Challenges for Public governance .433 Joanna Siekiera

Parte III - Resenhas 443

RESENHA DA OBRA

“Democracia e policentrismo do poder", de Murilo Gaspardo 445 Angela Limongi Alvarenga Alves 


\title{
Comparando la cultura jurídica desde el derecho a la identidad cultural en Brasil y Chile*
}

\author{
Comparing the Legal Culture from the \\ Perspective of the Right to Cultural Identity \\ in Brazil and Chile
}

\author{
Juan Jorge Faundes** \\ Fabien Le Bonniec***
}

\section{Resumen}

En este trabajo nos preguntamos qué transformaciones o conflictos se pueden identificar en las respectivas culturas jurídicas de Chile y Brasil, en relación a los nuevos marcos de reconocimiento de la identidad cultural de pueblos indígenas y otros grupos vulnerables. Al efecto, asumimos que para comparar ordenamientos jurídicos no basta con revisar solo el derecho positivo, sino que se debe contemplar el campo jurídico en su conjunto, en especial, la interacción de los textos normativos con la cultura jurídica de sus operadores. Desde esta perspectiva, buscamos, tanto, revisar comparadamente qué transformaciones y conflictos se visualizan en los respectivos campos jurídicos de Brasil y Chile respecto de su cultura jurídica y del derecho a la identidad cultural; como, proponer una metodología adecuada para realizar esta pesquisa comparativa de culturas jurídicas. Para ello: i) describimos algunos conceptos básicos sobre "la cultura jurídica"; ii) explicamos brevemente el derecho fundamental a la identidad cultural conforme los estándares definidos por la Corte IDH; iii) exponemos los enfoques metodológicos propuestos para la comparación de las culturas jurídicas en el campo jurídico chileno y brasileño; iv) presentamos una comparación de las culturas jurídicas de Chile y Brasil; v) concluimos exponiendo los principales hallazgos de la investigación.

Palabras clave: Cultura jurídica. Derecho identidad cultural. Comparación. Brasil. Chile.

Constitucionale Commune in América Latin (ICCAL) to a Euro-American dialogue on human rights, with focus on the fundamental right to cultural identity of minority groups" (enero y febrero de 2020), del Max Planck Institute for Comparative Public Law and International Law of Heidelberg (MPIL), Alemania. Agradecemos las invaluables contribuciones de la profesora Patricia Perrone Campos Mello, sin las cuales este artículo difícilmente hubiese sido logrado.

** Profesor, Universidad Autónoma de Chile. Email: juanjorgef@gmail.com

*** Profesor, Universidad Católica de Temuco. Email: fabien@uct.cl

\section{Abstract}

This work examines the transformations and conflicts related to the recognition of the cultural identity of indigenous peoples and other vulnerable groups, in the legal cultures of Chile and Brazil. We argue that the comparison of legal orders demands not only a study of their statutory law, but also an understanding of the legal culture of each country. Based in this conception, we compare transformations and conflicts related to the legal culture and to cultural identity in Brazil and Chile and simultaneously develop a 
specific methodology to carry out this comparative research of legal cultures. With this purpose, the paper: i) describes some basic concepts about legal culture; ii) briefly explains the scope of the right to cultural identity, as defined by the Inter-American Court of Human Rights; iii) proposes a methodological approach for comparing legal cultures in the Chilean and Brazilian legal fields; iv) presents a comparison of the legal cultures of these countries. The conclusion summarizes the main findings of the research.

Keywords: Legal culture. Right to cultural identity. Comparison. Brazil. Chile.

\section{Introducción}

En las tres últimas décadas los países de América Latina han alcanzado nuevas constituciones o realizado reformas constitucionales de reconocimiento de la diversidad cultural y de derechos de diversos grupos vulnerables. Al mismo tiempo, sentencias relevantes de los tribunales constitucionales y las cortes supremas han venido interpretando esas disposiciones. Estos cambios han introducido nuevos estatutos de derechos para los pueblos indígenas, grupos tribales, afrodescendientes y grupos vulnerables en general. Así, se afirma que toda esta dinámica ha generado importantes cambios en el campo jurídico, en la cultura jurídica, la cultura constitucional y la identidad cultural de los países latinoamericanos ${ }^{1}$.

Estas transformaciones, por una parte, se insertan en procesos más globales, con la suscripción de diversos instrumentos que reconocen derechos de naturaleza cultura $^{2}$, la aprobación de la Declaración de Naciones Unidas sobre Derechos de los Pueblos Indígenas y, en

FIGUEIREDO, Marcelo, Constitucionalismo Latino-Americano e Cultura Constitucional. En: VON BOGDANDY, Armin, PIOVESAN, Flávia, MORALES ANTONIAZZI, Mariela (Coords.): Constitucionalismo Transformador, Inclusacao e direitos coaciais: desafíos do IUS Constitucionale Commune Latino-Americano à la luz do Direito Econômico Internacional. Salvador: JusPODIVM, 2019. p. 725-752. p. 728-732.

2 Entre otros, v. "Convención para la salvaguardia del patrimonio cultural inmaterial" (Paris, 2003). Protege "el patrimonio cultural inmaterial (art. 1.a) ... de las comunidades, grupos e individuos..." (1.b); señala que el "patrimonio cultural inmaterial" comprende, entre otros: las (2.a) "tradiciones y expresiones orales, incluido el idioma", (2.c) los "usos sociales, rituales y actos festivos; los (2.d) "conocimientos y usos relacionados con la naturaleza y el universo; y las (2.e) "técnicas artesanales tradicionales". un grupo de países especialmente americanos, la ratificación del Convenio 169 de la OIT. Asimismo, en el plano regional propiamente tal, la Convención Americana de Derechos Humanos (CADH) y la jurisprudencia desarrollada por la Corte Interamericana de Derechos Humanos (Corte IDH), han tenido una sostenida influencia. La interacción de todas estas fuentes ha dado lugar a un conjunto de debates sobre la conformación jurisprudencial de un corpus iuris de derechos humanos latinoamericano ${ }^{3}$, con un desarrollo en particular respecto de derechos de los pueblos indígenas ${ }^{4}$ y otros grupos de matriz afrodescendiente ${ }^{5}$.

Destacamos la jurisprudencia de la Corte IDH porque desarrolla un conjunto de deberes para los actores jurídicos en relación con el derecho a la identidad cultural, habiendo señalando que se trata de un derecho de carácter fundamental y de naturaleza colectiva, que debe ser respetado en una sociedad multicultural, pluralista y democrática, que es "vía de interpretación transversal para concebir, respetar y garantizar el goce y ejercicio de los derechos humanos de los pueblos y comunidades indígenas protegidos por la Convención y por los ordenamientos jurídicos internos"

Sobre la idea de un Ius constitucionale comune en América Latina, v. BOGDANDY, Armin von; MORALES ANTONIAZZI, Mariela; FERRER MAC-GREGOR, Eduardo (coord). Ius Constitutionale Commune en América Latina: textos básicos para su Comprensión. Querétaro: Instituto de Estudios Constitucionales del Estado de Querétaro y MPI, 2017.

${ }^{4}$ v. AYLWIN, José; MEZA-LOPEHANDÍA, Matías; YAÑEZ, Nancy. Los pueblos indigenas y el derecho. Santiago: LOM, Observatorio Ciudadano, 2013. AGUILAR, Gonzalo. Emergencia de un derecho constitucional común en materia de pueblos indígenas. En: VON BOGDANDY, Armin; FERRER MAC-GREGOR, Eduardo, MORALES-ANZIONATTI, Mariela (eds.). La justicia constitucional y su internacionalización: ¿Hacia un Ius Constitucionale Commune en América Latina? Tomo II. México: UNAM, MPI, IIADC. 2010. p. 3-84.

5 La Corte IDH ha reconocido los derechos del referido corpus iuris de derechos de los pueblos indígenas, a diversos pueblos o grupos tribales de carácter afrodescendiente. V.: Corte IDH, Caso Aloeboetoe y otros Vs. Surinam, 10 septiembre de 1993 (Reparaciones y Costas); Corte IDH Caso de la Comunidad Moiwana Vs. Suriname, 15 junio de 2005 (Excepciones Preliminares, Fondo, reparaciones y Costas); Corte IDH, Caso del Pueblo Saramaka vs. Surinam, 28 noviembre de 2007 (Excepciones Preliminares, Fondo, Reparaciones y Costas); Corte IDH, Caso Comunidad Garífuna de Punta Piedra y sus miembros Vs. Honduras, 8 octubre de 2015 (Excepciones Preliminares, Fondo, Reparaciones y Costas).

6 Corte IDH, Caso del Pueblo Indígena Kichwa de Sarayaku vs. Ecuador, 27 junio 2012, p. 66, cons. 213 v. FAUNDES, Juan Jorge. El derecho fundamental a la identidad cultural de los pueblos indígenas: un derecho-matriz y filtro hermenéutico para las constituciones de América Latina: la justificación. Revista Brasileira de Politicas Públicas, v. 9, n. 2, 18 out 2019. p. 516. 
Así se sostiene que los diversos procesos normativos descritos, habrían venido conformando una nueva dogmática constitucional que transitó desde las comprensiones asimilacionistas e integracionistas, hasta la visión "multicultural" y la más reciente "plurinacional", que se habrían introducido -con diversos alcances e intensidades- en la cultura jurídica de los respectivos países de la región ${ }^{7}$. De esta forma -se plantea-, en el campo jurídico previo a estas transformaciones, las cuestiones culturales se situaban en lo que se consideraba “prejurídico", “extrajurídico”, “exótico”. Pero, bajo los nuevos diseños institucionales latinoamericanos, la cultura jurídica y la "cultura constitucional", en particular, incorporarían el derecho a la identidad cultural ${ }^{8}$, como una nueva categoría ius fundamental que desplazaría la matriz democrática igualitaria bajo una nueva matriz democrática "intercultural".

Paralelamente, también se plantean nuevas comprensiones de la cultura jurídica, que superan la visión estado-céntrica y poco disponible a la interacción con el Derecho Internacional de los Derechos Humanos, que introducen una nueva concepción interconectada -regional y globalmente- de los derechos humanos ${ }^{10}$.

FIGUEIREDO, Marcelo, Constitucionalismo Latino-Americano e Cultura Constitucional. En: VON BOGDANDY, Flávia Piovesan, Mariela Morales Antoniazzi (coods.). Constitucionalismo transformador, inclucao e direitos sociais: desafíos do IUS Constitucionale Commune Latino-Americano à la luz do Direito Econômico Internacional. Salvador: JusPODIVM, 2019. p. 725-752. p. 731-732. YRIGOYEN, Raquel, El horizonte del constitucionalismo pluralista: del multiculturalismo a la descolonización. En: RODRÍGUEZ, C. (coord.). El derecho en América Latina: un mapa para el pensamiento jurídico del siglo XXI. Buenos Aires: Siglo XXI, 2011. p. 139-159.

8 FIGUEIREDO, Marcelo. "Constitucionalismo Latino-Americano e Cultura Constitucional, en, Armin von Bogdandy, Flávia Piovesan, Mariela Morales Antoniazzi (coods.) Constitucionalismo transformador, inclucao e direitos sociais: desafíos do IUS Constitucionale Commune Latino-Americano à la luz do Direito Econômico Internacional. Salvador: JusPODIVM, 2019. p. 725-752, p.733, 734, 751.

9 Faundes, Juan Jorge. El derecho fundamental a la identidad cultural de los pueblos indígenas: un derecho matriz y filtro hermenéutico para las constituciones de América Latina: la justificación”. Revista Brasileira Políticas Públicas, v. 2, n. 2, ago. 2019. p. 513-535, p. 513, 521.

10 v.: BUSTOS, Rafael. Pluralismo constitucionaly diálogo jurisprudencial. México: Porrúa, 2012. p. 33; BUSTOS, Rafael. La Constitución red: un estudio sobre supraestatalidad y constitución. Bilbao: Instituto Vasco de Administración Pública, 2005. GARCÍA ROCA, Javier; FERNÁNDEZ SÁNCHEZ, Pablo; SANTOLAYA, Pablo; CANOSA, Raúl. El diálogo entre los sistemas europeo y americano de Derechos Humanos. 2. ed. Lima: ECB editores, 2015; PIZZOLO, Calogero. Comunidad de intérpretes finales: relación entre tribunales supranacionales, constitucionales y supremos: el diálogo judicial. Buenos Aires: ASTREA, 2017; MELLO, PERRONE, Patrícia. Constitucional-
Entonces, en este escenario de interconexión global y regional, en este trabajo nos preguntamos qué transformaciones o conflictos se pueden identificar en las respectivas culturas jurídicas de Chile y Brasil, en relación a los nuevos marcos de reconocimiento de la identidad cultural de pueblos indígenas y otros grupos vulnerables. Al efecto, solo preliminarmente, para perfilar estas culturas jurídicas, podemos señalar que en Chile, durante las últimas tres décadas (desde 1990 con el retorno a la democracia), se puede visualizar un proceso evolutivo de reconocimiento de derechos indígenas, en diversas materias, niveles jurisdiccionales (no exento de debates y conflictos). Esta evolución se ha configurado, en especial, por la ratificación de instrumentos internacionales como el convenio 169 de la OIT y una prolífera jurisprudencia de sus tribunales superiores. En Brasil, por su parte, a partir de la Constitución de 1988, interpretada progresivamente por la jurisprudencia del Supremo Tribunal Federal (STF), se ha introducido el reconocimiento de los derechos de los pueblos indígenas y de grupos tribales, con avances y también con tensiones.

De esta forma, observamos en ambos campos jurídicos un conjunto de factores, más o menos en común, relativos a la "la/las" "cultura/s jurídica/s" y su entendimiento en relación al derecho a la identidad cultural. Luego, este escenario, nos genera un interés desde dos perspectivas: primero, en términos concretos, nos parece que el examen de las dos experiencias indicadas puede arrojar luces respecto de qué transformaciones están ocurriendo en los campos jurídicos latinoamericanos, vale decir en el conjunto de sus actores, y qué caminos, eventualmente, podrían seguir estos procesos; segundo, observamos la importancia de plantear una metodología que pueda ser adecuada para abordar estas cuestiones, capaz de articular los aspectos normativos y los "extrajurídicos" de la cultura jurídica.

En el marco precedente, específicamente, nos planteamos la pregunta de si es posible comparar ordenamientos jurídicos tomando en cuenta solo el derecho positivo, sin considerar otros aspectos "extrajurídicos"

ismo, transformação e resiliência democrática no Brasil: o Ius Constitucionale Commune na América Latina tem uma contribuição a oferecer? Revista Brasileira de Políticas Públicas, Brasília, v. 9, n. 2, p. 253-285, 2019. p. 271-272. MELLO, PERRONE, Patrícia; FAUNDES, Juan Jorge. Constitucionalismo em rede: o direito à identidade cultural dos povos indígenas como filtro hermenêutico para tutela da tradicionalidade da ocupação da terra. In: CONGRESSO BRASILEIRO DE DIREITO SOCIOAMBIENTAL, 8., 2019, Paraná. Anais [...]. Paraná: PUC Paraná, 2019 (no prelo). 
(o no positivos) del campo jurídico, como la cultura jurídica (que comprende las prácticas, percepciones y preconcepciones de los sujetos que interactúan en este campo, a los "actores jurídicos"). Al efecto, desde ya, nuestra hipótesis es que para comparar ordenamientos jurídicos no basta considerar solo el derecho positivo, sino que se debe contemplar el campo jurídico en su conjunto; o, a lo menos, tomar en cuenta el máximo de factores posibles de aquellos que inciden en la creación, transformación y aplicación del Derecho, en especial, la interacción de los textos normativos con la cultura jurídica de sus operadores ${ }^{11}$.

En consecuencia, estudiamos el "Derecho" como un derecho en acción y emergente, comprensivo de la cultura y del campo jurídico en que se despliega. Entonces, en el Derecho - como campo jurídico en transformación permanente de sus componentes - los tribunales resuelven conforme al Derecho y bajo múltiples factores no jurídicos porque, al mismo tiempo, son espacios de producción y reconfiguración de identidades diferenciadas, que en su conjunto configuran la "cultura jurídica". Entonces, desde la perspectiva planteada, nuestra investigación busca: (a) revisar comparadamente qué transformaciones y conflictos se visualizan en los respectivos campos jurídicos de Brasil y Chile respecto de su cultura jurídica y del derecho a la identidad cultural de pueblos indígenas y tribales y (b) proponer una metodología adecuada para realizar esta pesquisa comparativa de culturas jurídicas. Para ello, este trabajo: i) describe algunos entendimientos conceptuales básicos sobre "la cultura jurídica"; ii) explica brevemente el derecho fundamental a la identidad cultural conforme los estándares definidos por la Corte IDH; iii) expone los enfoques metodológicos propuestos para la comparación de las culturas jurídicas en el campo jurídico chileno y brasileño; iv) presenta una comparación de las culturas jurídicas de Chile y Brasil; v) concluye exponiendo los principales hallazgos de la investigación.

\footnotetext{
11 En este sentido, dice López Medina: "En tiempos recientes la noción de cultura jurídica ha tenido auge importante en varias discusiones de teoría y sociología del derecho, tomándose como puente entre los conjuntos de normas, en su sentido más formal, y las prácticas sociales, en su sentido más antropológico. Si el sistema jurídico rige en un contexto social o entorno particular, se ha argüido, su existencia afectará y se verá afectada por la concreta cultura jurídica de dicho contexto o entorno". LÓPEZ MEDINA, Rocío del Carmen. Cultura jurídica, eunomía. Revista en Cultura de la Legalidad, n. 7, sep. 2014/feb. 2015. p. 229-235.
}

\section{La cultura jurídica, concepto y perspectivas}

Para Friedman, el sistema jurídico se compone de tres elementos. El elemento estructural, dado por las instituciones jurídicas, la forma y organización y los procedimientos diseñados para la operación de dicho sistema: tipo de cortes, división de poderes entre jueces, legisladores, gobernadores, jurados y oficiales administrativos; y los procedimientos en las diversas instituciones. El elemento sustantivo, conformado por las normas jurídicas, en particular en la medida que operan concreta y efectivamente en la vida social y que no han sido derogadas. El elemento cultural, dado por el conjunto de los valores y actitudes relacionados con el derecho. Luego, al definir cultura jurídica, presenta su clásica distinción entre cultura jurídica "interna" y "externa" 12 . La cultura jurídica externa corresponde al "conjunto de las ideas, valores, opiniones, expectativas y creencias que las personas en sociedad mantienen frente al sistema jurídico y sus diversos componentes"; la cultura jurídica externa corresponde a los entendimientos, acciones y orientaciones que prevalecen en la población de una sociedad sobre el Derecho y sistema legal ${ }^{13}$.

La cultura jurídica interna, específicamente, es "aquella que es propia de los miembros de la sociedad que realizan actividades jurídicas especializadas"; mediante la cultura jurídica interna "se pretende comprender la noción de derecho positivo a través de las actividades prácticas aplicadas para determinar los contenidos del sistema" ${ }^{14}$. Ella integra el "conjunto de actitudes, modos de expresarse, maneras de argumentar propio de los operadores jurídicos" ${ }^{" 15}$. La cultura jurídica interna está dada por "el conjunto de los valores, creencias, ideas, actitudes, prejuicios, orientaciones, prácticas, hábitos de trabajo, modos de pensar, y de sentir, que acerca del derecho prevalecen entre quienes se relacionan, con las estructuras e instituciones jurídicas de una manera directa, en razón de las profesiones u oficios que practican"16.

\footnotetext{
12 FRIEDMAN, Lawrence. The legal system: a social science perspective. New York: Russell Sage Foundation, 1975. p. 223.

13 SQUELLA, Agustín. La cultura jurídica chilena. Santiago de Chile: Corporación de promoción universitaria, 1988. p. 31.

14 LÓPEZ MEDINA. Rocío del Carmen, Cultura jurídica, Eunomía. Revista en Cultura de la Legalidad, n. 7, p. 229-235, septiembre 2014 - febrero 2015.

15 TARELLO, G. Cultura giuridica e politica del diritto, Il Mulino. Bologna, [S.n.], 1988. p. 24

16 SQUELLA, Agustín. Filosofía del Derecho. Santiago de Chile: Edi-
} 
Es decir, la cultura jurídica interna corresponde al desempeño profesional, de abogados, sean jueces, notarios u otros funcionarios de la administración de justicia, litigantes y profesores de Derecho, todos con educación jurídica formal ${ }^{17}$.

La segunda perspectiva, de la "cultura jurídica interna" o de "cultura en el derecho"18, es desde la cual se formula en este trabajo una propuesta metodológica para el estudio comparado de las transformaciones de la cultura jurídica en relación con el derecho fundamental a la identidad cultural, aplicada a los campos jurídicos de Chile y Brasil.

En el mismo sentido, López Medina señala tres dimensiones que componen la cultura jurídica (interna) -que consideraremos para definir el objeto de estudio comparado en nuestro estudio-. Primero, "una teoría del lenguaje", diferenciando disposición (texto legal) y norma (significado del enunciado legal). Segundo, "una teoría de la interpretación”, como "atribución de un significado normativo a una disposición”, como proceso hermenéutico en el que el significado jurídico es una variable determinada por las valoraciones y decisiones del intérprete, de los operadores jurídicos en particular. En nuestra investigación la cultura jurídica, precisamente, indaga sobre los enunciados normativos en concreto. Y tercero, una teoría del Derecho que, armónicamente con las dimensiones precedentes, entiende al Derecho como actividad doctrinal y jurisprudencial, por sobre la legislación misma. Desde esta perspectiva, el Derecho ya no se corresponderse solo con "la ley", el conjunto de enunciados normativos emanados del Poder legislativo, sino mucho más con "el conjunto de normas que de ellos extraen los intérpretes"19. Volveremos sobre estas comprensiones de la cultura jurídica al definir nuestras "unidades de comparación" desde el enfoque de David

torial Jurídica de Chile, 2001. p. 537. PAILLACURA, Darwin. La cultura jurídica chilena frente al derecho fundamental a la identidad cultural de los pueblos indígenas: un análisis del campo jurídico de la Araucanía. Tesis (Ciencias Jurídicas) - Universidad Católica de Temuco, 2019.

17 FUENZALIDA, Edmundo. Cultura jurídica externa e interna en el Chile finisecular: ¿Convergencia o divergencia? En: Anuario de filosofía jurídica y social. Sociedad chilena de filosofía jurídica y social. n. 20, 2000. p. 473-483, p. 473.

18 TARELLO, G. Cultura giuridica e politica del diritto, II Mulino. Bologna: [S.n], 1988. p. 24

19 LÓPEZ MEDINA, Rocío del Carmen, Cultura jurídica, Eunomía. Revista en Cultura de la Legalidad, n. 7, p. 229-235, septiembre 2014 - febrero 2015. p. 5.
Nelken.

La cultura jurídica se configura dinámicamente conforme cada contexto, por ello es complejo hablar de una "cultura jurídica latinoamericana", sino más bien de rasgos en común de diversas culturas jurídicas. De esta forma, para nuestro estudio, entonces, hablaremos de las culturas jurídicas desde los respectivos campos jurídicos chileno y brasileño. Ahora bien, "definir" la cultura jurídica chilena o la brasileña, en sí, por la propia naturaleza del concepto, también resulta difícil. No obstante, sí consideramos que es posible levantar descripciones, más o menos laxas o precisas, a lo menos, comprensivas de las formas de comportarse, de la toma de decisiones, de sus influencias, en el comportamiento de magistrados, fiscales y otros actores jurídicos, que podemos enmarcar dentro de lo que venimos llamando "cultura jurídica interna".

\section{El derecho fundamental a la identidad cultural configurado por la Corte IDH}

El derecho a la identidad cultural se fundamenta en un conjunto de normas del Derecho Internacional de los Derechos Humanos que refieren a la tutela de minorías culturales. Se puede definir como el derecho de las comunidades tradicionales y sus miembros a vivir de acuerdo con su cultura, y a ser reconocidos como diferentes en las relaciones con otros grupos, abarcando "el derecho a conservar su propia cultura, espiritualidad y referentes cosmogónicos, su patrimonio cultural tangible o intangible, su memoria histórica y su identidad presente ", así como "el derecho a que se respeten y protejan sus conocimientos, lengua, creencias, artes, moral, religión, formas de justicia y organización" ${ }^{20}$. Se trata de un derecho de naturaleza colectiva, de titularidad de las propias comunidades indígenas y también de grupos tribales afrodecendientes, con un doble alcance: (i) que se respete, valore y proteja su identidad y cultura frente al Estado y a terceros, con todos los bienes materiales e inmateriales que los componen; (ii) que su universo existencial, sus comportamientos y sus derechos sean

20 FAUNDES, Juan Jorge. Derecho fundamental a la identidad cultural de los pueblos indígenas: un nuevo paradigma en la defensa penal indígena en Chile frente al Estado de Derecho hegemónico. Revista Izquierdas, n. 45, p. 51-78, febrero 2019. p. 56-59. 
interpretados a la luz de tal identidad cultural. En estos términos, el derecho a la identidad cultural funciona, al mismo tiempo, como un contenido sustantivo que debe garantizarse y como un derecho matriz ${ }^{21}$ y filtrohermenéutico ${ }^{22}$ en relación a los demás derechos fundamentales de estos grupos. Constituye un punto de partida y un núcleo de significación de los demás derechos de dichas comunidades. Precisamente porque los miembros de cada comunidad sólo pueden ser comprendidos a la luz de su cultura, sus prácticas y sus significados, el derecho a la identidad cultural implica no sólo proteger manifestaciones identitarias y culturales, sino sobre todo, entender los comportamientos de cada comunidad a la luz de los significados que tal comunidad da a tales comportamientos y su visión del mundo - y no a la luz de los significados y la cosmovisión de la cultura dominante, a la cual de forma general pertenece el intérprete judicial.

En esta medida, este derecho produce una eficacia irradiante ${ }^{23}$ para todo el ordenamiento jurídico, por el cual determina que todo y cualquier derecho debe ser resignificado, reinterpretado o, al menos, contextualizado, basado en la cultura de la comunidad tradicional a la cual se aplicará. Al mismo tiempo, produce un mandato al intérprete del derecho a desplazarse de su centro hacia la comprensión "del otro", a la luz de la cultura de este último ${ }^{24}$.

Así, desde la perspectiva del derecho fundamental a la identidad cultural se pasan a revisar y reinterpre-

\footnotetext{
21 v.: FAUNDES Juan Jorge; RAMÍREZ Silvina (eds.). Derecho fundamental a la identidad cultural, abordajes plurales desde América Latina. Santiago: Universidad Autónoma de Chile, 2020 (en prensa).

22 FAUNDES Juan Jorge. El derecho fundamental a la identidad cultural de los pueblos indígenas: un derecho matriz y filtro hermenéutico para las constituciones de América Latina: la justificación. Revista Brasileira Politicas Públicas, v. 2 n. 2, p. 513-535, ago. 2019. Sobre la idea de "filtro hermenéutico" v: La concepción de filtro hermenéutico y la eficacia irradiante de los derechos fundamentales en el ordenamiento jurídico brasileño, v.:, p. 517. SOUZA NETO, Cláudio Pereira de; SARMENTO; Daniel. Direito constitucional: teoria história e métodos de trabalho. 2. ed. Belo Horizonte: Fórum, 2014. La formulación se inspira, a su vez, en el Derecho alemán, habiendo sido recogida de los debates sobre la eficacia irradiante de los derechos fundamentales. v. Tribunal Constitucional alemán, BVerfGE 7, "Caso Lüth", 198, 1958.

2.3 SARMENTO, Daniel. Direitos fundamentais e relações Privadas. 2. ed. Rio de Janeiro: Editora Lumen Juris, 2010. p. 64-75.

24 FAUNDES, Juan Jorge. Derechos humanos y el reconocimiento de la identidad cultural de los pueblos indígenas en América Latina, en la perspectiva crítica del descentramiento intercultural. En: OLVERA, Jorge; OLVERA, Julio y GUERRERO, Ana Luisa (coords.): Los pueblos originarios en los debates actuales de los derechos humanos. México: UNAM, CIAC, 2017, p. 39-60.
}

tar, en relación con pueblos, comunidades indígena y otros grupos afrodescendientes, categorías tales como: la propiedad indígena, el uso ancestral o tradicionalidad de la tierra (tradicionalidade) el derecho a los propios sistemas de justicia y la revisión penal de las conductas conforme los marcos culturales en que ocurrieron ${ }^{25}$; la revisión de los efectos intangibles -culturales- en materia ambiental no perceptibles para los terceros no miembros de pueblos indígenas ${ }^{26}$; y las formas propoias de organización, participación y la consulta indígena ${ }^{27}$. En este sentido, dijo la Corte IDH $^{28}$ :

[...] la significación especial que la tierra tiene para los pueblos indígenas en general... implica que toda denegación al goce o ejercicio de los derechos territoriales acarrea el menoscabo de valores muy representativos para los miembros de dichos pueblos, quienes corren el peligro de perder o sufrir daños irreparables en su vida e identidad y en el patrimonio cultural por transmitirse a las futuras generaciones $^{29}$.

\section{Enfoques metodológicos para la comparación de la cultura jurídica}

Como indicamos introductoriamente, nuestro objetivo es el estudio comparado de las potenciales trans-

${ }_{25}$ KALINSKY, Beatriz. Justicia, Cultura y Derecho Penal. Buenos Aires: Ad-Hoc S.R.L, 2000, pp. 156-161. DE MAGLIE, Cristina. Los delitos culturalmente motivados ideologías y modelos penales. Madrid: Marcial Pons, 2012, pp.193-237. FAUNDES, Juan Jorge. Derecho fundamental a la identidad cultural de los pueblos indígenas: un nuevo paradigma en la defensa penal indígena en Chile frente al Estado de Derecho hegemónico. En: Revista Irquierdas, n. 45, p. 51-78, febrero 2019. p. 56-58.

26 CARMONA, Cristóbal. La aplicación del derecho a consulta del Convenio 169 de la OIT en Chile: hacia una definición de su contenido sustantivo: afectación e instituciones representativas. En: MIRANDA, Ricardo y CARMONA, Cristóbal. Tesis (maestría) sobre Pueblos Indígenas, v.3. Colección Tesis de Maestría U. Nacional San Martín de Buenos Aires. Buenos Aires: U. Nacional de San Martín, CIEP, 2013. p. 83. FAUNDES, Juan Jorge. Consulta indígena y centrales de generación hidroeléctrica de menos de 3MW: desregulación riesgosa, a la luz del derecho fundamental a la identidad cultural de los pueblos indígenas. En: Libro III Congreso Internacional de Regulación y Consumo. Santiago: RIL, Universidad Autónoma de Chile, 2020. p. 369-373.

27 v.: FAUNDES, Juan Jorge, El derecho fundamental a la identidad cultural de los pueblos indígenas, configuración conforme el derecho internacional y perspectivas de su recepción en Chile. Revista Ius et Praxis, n. 1, 2020.

28 Caso de la Comunidad Indígena Sawhoyamaxa Vs. Paraguay. Sentencia de 29 de marzo de 2006

29 Caso de la Comunidad Indígena Sawhoyamaxa Vs. Paraguay. Sentencia de 29 de marzo de 2006, prr. 98. 
formaciones en la cultura jurídica, focalizada en la recepción del derecho a la identidad cultural de pueblos indígenas y otros grupos vulnerables, aplicada a los campos jurídicos de Chile y Brasil. Para ello, presentamos una metodología interdisciplinaria, con la finalidad de comprender las dinámicas jurídicas de creación, transformación y aplicación del Derecho, considerando a los indígenas y a otros miembros de grupos culturalmente identitarios -como los quilombolas de Brasil- en tanto sujetos destinatarios del Derecho, pero también como actores partícipes del Derecho. En este sentido, si bien nos focalizamos en la "cultura jurídica interna", la entendemos en interacción con los actores jurídicos destinatarios de las normas, como una dimensión de la cultura jurídica porosa y comunicada con los demás componentes del campo jurídico. Bajo este enfoque, buscamos desarrollar una metodología creativa que excede la Ciencia Jurídica - en sentido ortodoxo. Por ello, entre otros aspectos, se integra la etnografía dentro de las técnicas metodológicas.

$\mathrm{Al}$ mismo tiempo, planteamos una estrategia de investigación desde la perspectiva del Derecho comparado, aplicada a la comparación de culturas jurídicas, siguiendo a Nelken ${ }^{30}$.

\subsection{Cultura jurídica, en perspectiva metodológica de derecho comparado}

En lo que atañe al Derecho, estudios comparados como el nuestro pueden inscribirse en lo que Siems llama "other forms of comparative law", esto es, otras escuelas que tienen en común "la desaprobación del legalismo y doctrinalismo asociado a los tradicionalistas", que aportan ventajas, en especial, para el estudio de la cultura jurídica de los países Quizás, podemos decir nosotros, que estos enfoques aportan alternativas metodológicas al legalismo ya que consideran que comparar solo las normas legales es insuficiente y que, como mínimo, el ejercicio comparativo debiera "basarse en un entendimiento de las teorías y valores subyacentes a los órdenes legales" 31 .

En el mismo sentido, Siems advierte explica que "este enfoque es epistemológicamente más abierto" y

\footnotetext{
30 NELKEN, David (ed.). Comparing legal cultures. Vermonth: Darmonuth Publishing Company, 1997.

31 SIEMS, Mathias. Comparative Law (Law in context). 2. ed. Cambridge: Cambridge University Press, 2018. p. 113-115.
}

está asociado con estudios culturales, "implica un rechazo del funcionalismo, bajo la prevalencia de narrativas locales", con un énfasis en la pluralidad, intersubjetividad, experiencia, conocimiento situado, en la hermenéutica e hibridación. Señala que estas corrientes rechazan el funcionalismo del derecho comparado ${ }^{32} \mathrm{y}$, a menudo, favorecen la especificidad local, enfatizando el rol de la cultura, la pluralidad y la subjetividad. En este sentido, como venimos planteando, dado que la cultura jurídica -aunque incluye las estructuras jurídicas formales-, excede las instituciones de elaboración de las leyes y aplicación del Derecho. Luego, como emergen otras formas de creación del orden social, metodológicamente, "se necesita considerar los tipos informales de control social y de resolución de conflictos". Entonces, en especial, la comparación debe incluir los hábitos y actitudes de los operadores que las sustentan ${ }^{33}$.

32 El método funcionalista incorpora la perspectiva de la teoría de sistemas en el derecho, en general propone la comprensión y explicación de las estructuras sociales a partir de la observación, análisis y estudio de las funciones o del funcionamiento de las estructuras sociales dentro de la sociedad (sistémicamente) o en parte de ella y no desde su origen histórico, de las contextuales y temporales. En particular, para Luhmann el Derecho corresponde a "un subsistema específico del complejo sistema social, definido básicamente por la nota de positividad, y que se diferencia funcionalmente de los otros subsistemas sociales (económico, moral, político, etc.) por su entramado de comunicación consistente en su propio sistema binario -distinción entre lo jurídico (Recht) y lo antijurídico (Unrecht)- capaz de establecer y fijar determinadas 'expectativas normativas de conducta”'. MONTORO BALLESTEROS, Alberto, El funcionalismo en el Derecho: Notas sobre N. Luhmann y G. Jakobs. Anuario de Derechos Humanos. Nueva Época, v. 8, pp. 365-374, 2007. p. 365369.

Sobre el funcionalismo comparativo, en particular, Siems explica que esta corriente afirmó que las instituciones que abordaban las necesidades sociales eran bastante similares en todas las sociedades. En este sentido, que la equivalencia funcional reside en el hecho de que unidades de análisis diferentes pueden agruparse en categorías significativas (comparables). En síntesis, la clave de la comparación radicaría en identificar "un equivalente funcional en el derecho interno". Entonces, bajo el funcionalismo, la comparación requiere "comparabilidad", luego, incomparables no pueden ser útilmente comparados y las únicas normas comparables serían las que cumplen la misma función. Por lo tanto, la comparación funcional dejaría al margen incluso una comparación de reglas bastante similares, si en los países en cuestión cumplen diferentes funciones. Además, la comparación solo podría ser entre sistemas iguales, esto es, que estén en similares condiciones normativas, políticas y económicas. O bien, con frecuencia la comparación funcional excluye materias en las que las condiciones geográficas u otras de contexto influencien las unidades en comparación. Ante las críticas - dice Siems -, el funcionalismo ha ido cediendo gradualmente frente a enfoques culturales y hermenéuticos SIEMS, Mathias. Comparative Law (Law in context). 2. ed. Cambridge: Cambridge University Press, 2018. p. 31-34 (síntesis desde traducción propia).

33 SIEMS, Mathias. Comparative Law (Law in context). 2. ed. Cam- 


\subsection{Delimitando las "unidades" para la comparación de culturas jurídicas}

Para establecer nuestras "unidades" de comparación seguimos a David Nelken en las prevenciones que plantea sobre los límites y variaciones posibles para la comparación de culturas jurídicas ${ }^{34}$. Señala que un enfoque comparativo centrado en la cultura jurídica requiere examinar las interconexiones entre el Derecho, la sociedad y la cultura, interrelacionadas como "Derecho en acción" y "Derecho vivo", que dicen especial relación al rol del Estado de derecho en las sociedades ${ }^{35}$.

Agrega que, si bien el concepto de cultura jurídica es un concepto aplicable a las investigaciones comparativas empíricas, requiere operacionalizar el concepto de cultura. En particular indica que Friedman utilizó la noción de cultura con excesiva amplitud - "desde la cultura del individuo, hasta la de sociedades enteras”. Al efecto, señala que Friedman define la cultura jurídica como una gran superposición de múltiples niveles de cultura que varían en contenido, alcance e influencia en su relación con las instituciones de los sistemas jurídicos estatales. Luego, para Nelken, esa amplitud de niveles y de unidades super nacionales y subnacionales, si bien podría proporcionar un buen espacio para las investigaciones comparativas, al mismo tiempo, ese marco tan amplio y complejo impide la comparación ${ }^{36}$. Pero, al mismo tiempo, al definir un nivel de comparación nacional no se puede limitar la investigación solo al Estado nación.

En consecuencia, aunque se ubique la cultura jurídica en un nivel, ella comprende una variedad de unidades diferentes, conectadas, todas en permanente cambio, en un contexto de interacción mutua con las demás. Estas unidades dan forma a la vida social de varias maneras. Por ejemplo, a través de en memorias, tradiciones históricas, en tipos de prácticas, actitudes, expectativas y

bridge: Cambridge University Press, 2018. p. 116, 148-149 (Traducción libre).

34 NELKEN, David. Defining and using the Concept of jurídica Culture. En: Maurice Adams, Jaakko Husa and Marieke Oderkerk (ed.). Comparative Law Methodology. V. 2. Massachusets: EE Elgar, 2017. p. 332-355.

35 NELKEN, David. Defining and using the Concept of jurídica Culture. En: Maurice Adams, Jaakko Husa and Marieke Oderkerk (ed.). Comparative Law Methodology. V. 2. Massachusets: EE Elgar, 2017. p. 332-355. p. 333

36 NELKEN, David. Defining and using the Concept of jurídica Culture. En: Maurice Adams, Jaakko Husa and Marieke Oderkerk (ed.). Comparative Law Methodology. V. 2. Massachusets: EE Elgar, 2017. p. 332-355. p. 339. formas de pensar, rutinas organizativas y socialización profesional. Entonces, para Nelken, más que demostrar la coherencia entre unidades (tan diversas), el desafío reside en desarrollar un método que permita la comparación asumiendo "las complejidades de la cultura jurídica vivida con su mezcla de elementos superpuestos y potencialmente competitivos". Desde esta perspectiva, serían tres las vías para alcanzar un método que identifique unidades que resulten coherentes para comparar:

(1) cuando existe un vínculo intrínseco entre los elementos que componen la unidad;

(2) cuando la conexión exista en la medida en que los participantes hablen sobre ella, como si ella existiera; o

(3) que la supuesta coherencia sea impuesta a las unidades por el investigador, por ejemplo, a través de procesos de categorización o la construcción de tipos ideales ${ }^{37}$

En este marco, para Nelken, la comparación en el primer supuesto de vínculo intrínseco de coherencia interna se puede focalizar en: (i) los aspectos que mantienen unidas determinadas de cultura jurídica interna o externa; (ii) la política cultural o la cultura económica, que define dicha unidad; (iii) la relación entre la cultura jurídica y la cultura general; (iv) definiendo determinadas unidades dadas de culturas jurídicas para ser comparadas con otras que corresponde a la comparación de culturas jurídicas más amplias (a menudo nacionales) en que se suele poner más énfasis en las prácticas y en las valoraciones sociales; (v) estableciendo "determinados tipos ideales de comunidad que tienen diferentes propensiones para estructurar sus relaciones como Derecho" ${ }^{38}$. El autor plantea algunas advertencias para comparar en estos casos. Por ejemplo:

En el tercer aspecto de la coherencia, si bien la dirección de influencia es principalmente de la cultura en general hacia la cultura jurídica en particular, también pueden ocurrir transformaciones en la cultura general a partir de las prácticas, comportamientos e ideas en particular. Luego, en este caso, el método debe ser capaz

37 NELKEN, David. Defining and using the Concept of jurídica Culture. En: Maurice Adams, Jaakko Husa and Marieke Oderkerk (ed.). Comparative Law Methodology. v. 2. Massachusets: EE Elgar, 2017. p. 332-355. p. 343.

38 NELKEN, David. Defining and using the Concept of jurídica Culture". En: Maurice Adams, Jaakko Husa and Marieke Oderkerk (ed.). Comparative Law Methodology. v. 2. Massachusets: EE Elgar, 2017. p. 332-355. p. 345. 
de dar cuenta de este doble sentido de interacción ${ }^{39}$. Al efecto, se evidenciará, en relación con el ejercicio del derecho a la identidad cultural, que, por una parte, existen fenómenos globales que amplían los marcos culturales en relación con la diversidad, pero, también, el propio ejercicio del derecho a la identidad cultural va asentando el mismo derecho ${ }^{40}$.

Señala que estas vías no son fijas ni cerradas porque, por ejemplo, con frecuencia los participantes piensan que están tratando de hacer algo -lo hagan o no, lo logren o no-, ya que esto es lo que da significado y propósito de sus acciones; o bien, al definir los límites de las unidades de comparación, bien se puede categorizar y con ello imponer coherencia cultural, bajo los patrones pre dados por el investigador. En particular, advierte Nelken, la importancia de evitar "las afirmaciones sobre la existencia de patrones culturales que luego ayudan a traerlos a la existencia" (efecto circular). Por ello, ante la práctica de la categorización ideal, advierte en la necesidad de procurar pesquisas descriptivas (clasificación, mapeo y descripción), más que en la demostración de categorías hipotéticas que terminen imponiendo el resultado (de la hipótesis) ${ }^{41}$.

Destaca la diferencia entre focalizar la comparación en un enfoque hermenéutico ("giro interpretativo"), versus una concepción positivista centrada en el comportamiento. Al efecto indica que "el enfoque positivista buscaría arrojar luz sobre la cultura jurídica tratando de asignar prioridad causal entre variables e hipótesis competidoras, que expliquen la variación en los niveles y tipos de comportamiento jurídicamente relacionado". Mientras, "el enfoque interpretativo, por otro lado, es más interesado en proporcionar 'de espesor a las descripciones del derecho como conocimiento local" - siguiendo Geertz. En este caso, la preocupación de la comparación radica en cómo "traducir las ideas de justicia de otro sistema e imparcialidad para hacer que el

\footnotetext{
39 NELKEN, David. Defining and using the Concept of jurídica Culture". En: Maurice Adams, Jaakko Husa and Marieke Oderkerk (ed.). Comparative Law Methodology. v. 2. Massachusets: EE Elgar, 2017. p. 332-355. p. 345.

40 NELKEN, David. Defining and using the Concept of jurídica Culture". En: Maurice Adams, Jaakko Husa and Marieke Oderkerk (ed.). Comparative Law Methodology. v. 2. Massachusets: EE Elgar, 2017. p. 332-355. p. 345.

${ }^{41}$ NELKEN, David. Defining and using the Concept of jurídica Culture". En: Maurice Adams, Jaakko Husa and Marieke Oderkerk (ed.). Comparative Law Methodology. v. 2. Massachusets: EE Elgar, 2017. p. 332-355. p. 344-345.
}

sentido de la red sea significativo ${ }^{42}$. Este enfoque busca la comparación y potencial identificación de elementos comunes de significado entre las culturas jurídicas y sus campos, en comparación.

Destacando una clave para el método, señala Nelken que la preocupación debe recaer en que "los enlaces que estamos describiendo sean de alguna manera intrínsecos al objeto que se describe". Así, la llave para salvar los problemas de la comparación de culturas jurídicas se encontraría en no categorizar (en exceso) las búsquedas, en no suponer necesariamente que todas las transformaciones dicen relación a la cultura jurídica ("mostrar que los valores culturales causan una respuesta dada a los eventos"43). Y sí es relevante formular preguntas adecuadas para pesquisar qué cambió - si es que algo cambió - y no para demostrar un cambio determinado (en un sentido deseado o esperado por el investigador).

Así, en primer término, usando las dimensiones que componen la cultura jurídica (interna) -según vimos desde López Medina-, nuestra comparación iniciará con el texto constitucional y seguirá mostrando su interpretación por los tribunales con competencia constitucional. Al efecto, se considerará el significado jurídico como una variable determinada por las valoraciones y decisiones de los operadores jurídicos en particular. Y, finalmente, como hemos dicho, entenderemos el Derecho, ampliamente, como campo jurídico.

Asimismo, recogiendo las prevenciones de Nelken que buscan delimitar la comparación de culturas jurídicas: (i) referiremos a "culturas jurídicas" en campos jurídicos de nivel nacional y no a una cultura jurídica regional; (ii) la comparación será entre las culturas jurídicas (unidades) de los campos jurídicos brasileño y chileno; (iii) la definición general de estos niveles delimita la comparación, pero no excluye la composición compleja y dinámica de las culturas jurídicas y sus interacciones. Para el abordaje indicado, la estrategia metodológica considera el uso de preguntas de investigación descriptivas y no inductivas (evitando el uso de tipos ideales). Con todo, sí se utiliza la categoría de derecho a

42 NELKEN, David. Defining and using the Concept of jurídica Culture". En: Maurice Adams, Jaakko Husa and Marieke Oderkerk (ed.). Comparative Law Methodology. v. 2. Massachusets: EE Elgar, 2017. p. 332-355. p. 345.

43 NELKEN, David. Defining and using the Concept of jurídica Culture". En: Maurice Adams, Jaakko Husa and Marieke Oderkerk (ed.). Comparative Law Methodology. v. 2. Massachusets: EE Elgar, 2017. p. 332-355. p. 345-346. 
la identidad cultural, porque es parte del marco normativo cuyo alcance efectivo y eventuales efectos la investigación busca determinar.

Así, la comparación usará tres aspectos del nivel nacional: (1) el texto constitucional en los aspectos relevantes a la identidad cultural; (2) la interpretación de ese texto dada por tribunales con competencia constitucional en precedentes destacados; (3) las percepciones de los operadores jurídicos (en su respectivo campo), respecto la interacción del derecho a la identidad cultural y la cultura jurídica.

Como el nivel de comparación está dado por los campos jurídicos nacionales, considerando las diversas interacciones internas, los operadores jurídicos considerados en el estudio intervienen en tribunales de diversas competencias jurisdiccionales y cumplen diferentes funciones. En este sentido, nos importan sus percepciones sobre la cultura jurídica en relación con el derecho a la identidad cultural y no es gravitante la función en particular que desempeñan.

\subsection{Metodologías para estudiar la cultura jurídica desde las ciencias sociales}

En este trabajo se seguirá un enfoque socio-antropológico. Al respecto, el marco analítico ofrecido por Pierre Bourdieu, al aprehender el Derecho como un campo social, se requiere una metodología particular, a la misma vez interdisciplinaria y ecléctica, que permita dar cuenta de las respectivas posiciones estructurales de los actores que la componen y de los capitales que movilizan en el marco de sus pugnas de poderes y prestigios, y como estas luchas se dan en el terreno de la cultura jurídica, en la legitimidad de decir, definir e interpretar el Derecho. Según Bruno Latour ${ }^{44}$, en los estudios Law and Society, se trata de retomar el "derecho en acción", estudiarlo tal como se produce y no solo como se dice o afirma, ${ }^{45}$ lo que implica interesarse no solo en los actores y sus propiedades sociales, sino en cómo se van configurando las controversias jurídicas. Ello será central en torno a la emergencia del derecho a la identidad cultural y los razonamientos jurídicos asociados a ella, en función de sus diversos contextos de

${ }_{44}$ LATOUR, Bruno. La fabrique du droit: une ethnographie du Conseil d'État. Paris: La Découverte, 2002.

45 DUPRET, Baudouin. Droit et sciences sociales. Pour une respécification praxéologique. Droit et société, v. 2, n. 75, p. 315-335, 2010. enunciación. En este sentido, la cultura jurídica constituye un fundamento central del sistema de creencias, el ilusio $^{46}$, en cual se mueven los propios actores jurídicos, que va modelando sus maneras de ser y pensar, su habitus, desvelando su estrecha relación con el campo jurídico. El estudio de las transformaciones de estos ámbitos implica la aprehensión de la evolución de las prácticas, discursos y razonamientos jurídicos en relación con los usos de las normas.

Por otra parte, al ofrecer una distinción entre "derecho objetivo" y "derechos subjetivos" Max Weber ${ }^{47}$ ha matizado las relaciones y tensiones entre estas dos dimensiones que son la base de las transformaciones legales y la posible emergencia de nuevos derechos ${ }^{48}$. Desde entonces, los estudios sobre Derecho, como es el caso de la tradición de los Law and Society, han tratado de superar la dicotomía entre la perspectiva internalista y externalista para tratar la problemática de la interrelación entre mundos sociales y jurídicos. Esta perspectiva ha llevado a concebir el derecho bajo distintos prismas, ya sea como una "actividad social" ${ }^{49}$ o como un sistema social autopoiético ${ }^{50} \mathrm{o}$ incluso como el resultado de una cadena de producción o traducción ${ }^{51}$. La creciente confluencia del campo jurídico con el campo político marca un momento de "judicialización" en la sociedad, donde el primero intenta expandirse sobre el otro ${ }^{52}$, derivando a la protección legal y normalización de los derechos de los grupos minoritarios, como los pueblos indígenas y los afrodescendientes.

Por su parte, los estudios que abordan la transformación de la justicia y del Derecho en América Latina, son profusos y variados, se interesan tanto en las reformas de sus instituciones ${ }^{53}$, en la evolución de sus

46 BOURDIEU, Pierre. Les juristes, gardiens de l'hypocrisie collective. En: CHAZEL, François; COMMAILLE, Jacques (eds.). Normes juridiques et régulation sociale Paris : LGDJ, collection Droit et société, 1991, p. 95-99. 1991.

47 WEBER, Max. Economía y sociedad. México: Fondo de Cultura Económica, 2014.

48 COLLIOT-THÉLÈNE, Catherine. La sociologie de Max Weber. Paris: La découverte, 2006.

49 DEWEY, John. La formation des valeurs. Paris : La Découverte, 2011.

50 LUHMANN, Niklas. El derecho de la sociedad. México: Universidad Iberoamericana, 2002.

51 LATOUR, Bruno. La fabrique du droit : une ethnographie du Conseil d'État. Paris: La Découverte, 2002.

52 TATE, C. Neal; VALLINDER, Torbjorn. The Global Expansion of Judicial Power. New York: New York University Press, 1995.

53 SOUSA, Mariana. Breve panorama de la reforma judicial en América Latina: objetivos, desafíos y resultados. En: LORA, ED- 
actores $^{54} \mathrm{y}$ formaciones ${ }^{55}$, en la apertura hacia la interlegalidad ${ }^{56}$ o el pluralismo jurídico ${ }^{57}$, de la mano de las reformas constitucionales implementadas en varios países latinoamericanos en estas últimas décadas ${ }^{58}$ y el surgimiento de los nuevos constitucionalismos ${ }^{59}$.

Con todo -como se planteado-, si bien la indagación de la hermenéutica constitucional en las sentencias es muy relevante, no es suficiente para describir las transformaciones en el campo jurídico, considerando sus interacciones, actores, etc., ya que los fallos, por ejemplo, no son siempre explícitos en cuanto a los argumentos esgrimidos por cada parte, la forma de expresarlos, no pueden restituir todas las dinámicas de un juicio, no consideran el cumplimiento o incumplimiento de ellos, o no es posible medir directamente su incidencia en la formación jurídica ${ }^{60}$. En este sentido, como son producto del razonamiento jurídico de los sentenciadores y muchas veces de los acuerdos estratégicos entre ellos, tampoco representan, necesariamente, una muestra significativa de los conflictos, posiciones, efectivamente presentados ante los jueces ${ }^{61}$. Por ello, nos importa aprehender la rea-

UARDO (Org.). El estado de las reformas del Estado en América Latina. Bogotá: Banco Mundial del Desarrollo, 2007. p. 99-137.

54 PÁSARA, Luis (ed.). Los actores de la justicia Latinoamericana. Salamanca: Universidad de Salamanca, 2007.

55 BINDER, Alberto. Los oficios del jurista: la fragmentación de la profesión jurídica y la uniformidad de la carrera judicial. Academia: revista sobre enseñanza del derecho de Buenos Aires, n. 5, p. 85-116, 2005.

56 SANTOS, Boaventura de Sousa. Toward a new common sense: law, science and politics in the paradigmatic transition. New York: Routledge, 1995.

57 YRIGOYEN, Raquel. Pluralismo jurídico y jurisdicción indígena en el horizonte del constitucionalismo pluralista. In: AHRENS, HELEN (Org.). El Estado de derecho hoy en América Latina: libro homenaje a Horst Schönbohm. Montevideo: Editorial Konrad-Adenauer-Stiftung E.V., 2012. p. 171-194.

58 SIEDER, Rachel. Pueblos indígenas y derecho (s) en América Latina. En: RODRÍGUEZ, César (ed). El derecho en América Latina: un mapa para el pensamiento jurídico del siglo XXI. Buenos Aires: Siglo XXI, p. 302-321.

59 RAMÍREZ, Silvina. Siete problemas del Nuevo Constitucionalismo indígena. En: YRIGOYEN, Raquel (ed.). Pueblos Indígenas: constituciones y reformas políticas en América Latina. Lima: ILSA, INESC, IIDS, 2010. CAMPOS MELLO, PERRONE, Patricia, Constitucionalismo, transformação e resiliência democrática no Brasil: o Ius Constitucionale Commune na América Latina tem uma contribuição a oferecer? Revista Brasileira de Políticas Públicas, v. 9, n. 2, p.253-285, 2019. p. 271-272.

60 DE LA SIERRA, Susana. Una metodología para el Derecho Comparado europeo: derecho Público Comparado y Derecho Administrativo Europeo. Madrid: Thomson, Civitas, Arazandi, 2004. p. 74-77.

${ }^{61}$ Sobre comportamiento estratégico y factores extrajurídicos de las decisiones judiciales v. CAMPOS MELLO, PERRONE, Patricia. Nos bastidores do Supremo Tribunal Federal. Rio de Janeiro: Forense, 2015. lidad, el contexto asociado a la decisión judicial, metodológicamente, a través de la observación etnográfica y las entrevistas a los operadores jurídicos, los actores del sistema jurídico en acción, para de esa forma pesquisar en torno a la cultura jurídica y el derecho a la identidad cultural en los campos jurídicos de Chile y Brasil.

\subsection{Metodología aplicada para el estudio comparado de la cultura jurídica en los campos jurídicos de Chile y Brasil}

En este apartado se desarrolla una propuesta metodológica focalizamos en la denominada "etnografía del Estado". Esta perspectiva asume al Estado como una entidad que se constituye en una formación cultural y moral de sus agentes, sus instituciones, sus representaciones y producciones jurídicas en vía de transformación multicultural ${ }^{62}$.

Luego, nuestro objetivo en esta tercera dimensión de la comparación es visualizar las transformaciones del campo jurídico y la cultura jurídica a partir de la interacción de los diversos espacios en que los operadores jurídicos conforman y aplican el derecho fundamental a la identidad cultural. Al efecto, la propuesta de metodología aplicada busca, en particular, alcanzar: (i) una descripción de la cultura jurídica desde la comprensión de los operadores del respectivo campo jurídico; (ii) una descripción desde los actores del campo jurídico, de cómo esa cultura jurídica ha recepcionado el derecho a la identidad cultural. Así (conforme las referencias ya realizadas a Friedman, López y Siems), se indagará cómo los operadores del campo jurídico visualizan (i) las estructuras e instituciones, (ii) los valores culturales, hábitos, ideologías, intereses, prejuicios y discursos preponderantes que promueven los operadores del sistema, en relación con el derecho a la identidad cultural en cada uno de los campos jurídicos estudiados.

Respecto de esta dimensión, la estrategia de la investigación aplicada contó con una fase inicial en Chile, mediante la cual se modeló la metodología de este estudio y una segunda fase en Brasil, en que se probó la metodología de forma piloto y se levantó información para una comparación preliminar entre las culturas jurídicas en la materia.

62 BOLADOS GARCÍA, Paola; BOCCARA, Guillaume. Du néolibéralisme multiculturel aux mobilisations post-multiculturelles. Actuel Marx, v. 56, n. 2, p. 74, 2014. 


\section{La fase de modelaje en Chile de la propuesta metodológica aplicada:}

En la primera etapa, la investigación empírica se realizó entre 2016 y 2019, estudiando las transformaciones del campo jurídico, focalizadas en la cultura jurídica chilena, frente al derecho a la identidad cultural de integrantes del Pueblo Mapuche ${ }^{63}$. El estudio se centró en tribunales penales en las regiones del Bio Bio, de la Araucanía y de los Rios. Metodológicamente, se utilizaron entrevistas semi estructuradas a los actores jurídicos y se construyó un relato usando la transcripción de las respuestas. Se usó la técnica de la saturación, seleccionaron las percepciones de los operadores (declaradas) en que existe armonía entre las respuestas de los entrevistados y muchas veces hubo coincidencia, de tal forma de presentar los resultados de mayor consistencia.

Las preguntas base de la entrevista semi estructurada seleccionadas para el trabajo comparativo entre culturas jurídicas fueron: ¿qué entiende Ud. por cultura jurídica? ¿Qué entiende usted por identidad cultural?; ¿identifica el derecho a la identidad cultural en la cultura jurídica (chilena/brasileña)?; y, si la última respuesta fue afirmativa, se consultó: ¿qué interacciones visualiza entre la cultura jurídica y el derecho a la identidad cultural?. La entrevista también contó con preguntas dirigidas a la identificación personal y del área de desempeño del actor jurídico entrevistado; además, se usaron otras preguntas destinadas a pesquisar elementos relevantes en relación a la cultura jurídica y el derecho a la identidad cultural, pero que muchas veces eran integrados en las

63 El Pueblo Mapuche se ubica territorialmente en las regiones chilenas del Bio Bio, de Los Ríos, en la Metropolitana (Santiago) y, principalmente en la IX Región "de la Araucanía”, donde se focalizó nuestro estudio. Además, existe presencia mapuche minoritaria binacional en los sectores limítrofes de Chile con Argentina en la misma latitud de la Araucanía.

La distribución de la población indígena chilena es de 2.185.792 habitantes a 2017 y su composición es heterogénea de nueve pueblos indígenas reconocidos. A 2017 el Pueblo Mapuche es el pueblo indígena con mayor población del país con 1.745 .147 que corresponde a un $9,9 \%$ de la población chilena (de un total de 17.574 .003 de habitantes). La población mapuche, a su vez, constituye el $79 \%$ del total nacional de personas que se declaran indígenas. EL 11\% de los mapuche viven en la Región del Bío Bio y el 37\% en La Araucanía. MINISTERIO DE PLANIFICACION NACIONAL Y POLITICA ECONOMICA. Instituto Nacional de Estadísticas. 2018. Síntesis de resultados Censo 2017. Disponible en: https:/ /www.censo2017.cl/descargas/home/sintesis-de-resultados-censo2017.pdf MINISTERIO DE PLANIFICACION NACIONAL Y POLITICA ECONOMICA. Instituto Nacional de Estadísticas. Estadísticas sociales de los pueblos indígenas en Chile. Censo 2002. Cruce de datos propio. respuestas a las preguntas base, por lo que estas interrogaciones secundarias eran omitidas en esos casos o solo usadas como verificadoras del relato ${ }^{64}$.

Las entrevistas realizadas a los actores jurídicos permitieron recolectar informaciones acerca de sus características sociales, su trayectoria, su quehacer, su posición ante la diversidad cultural en los tribunales y su percepción de la transformación del derecho, además de su reflexión sobre sus propias prácticas. Además de algunos jueces, fiscales y abogados de la macrorregión sur de Chile, se realizaron entrevistas a otros actores relevantes como un ministro de la Corte Suprema a cargo de políticas de acceso a la justicia de poblaciones vulnerables $^{65}$. La descripción contextual del campo jurídico y de la cultura jurídica chilena fue complementada y cotejada con información de fuentes secundarias, principalmente bibliográficas.

Finalizando este apartado, es importante advertir que la investigación chilena en referencia, si bien considera entrevistas a actores jurídicos de diversos ámbitos jurisdiccionales, se focalizó en actores los tribunales de competencia penal, en las regiones de mayor presencia de población indígena mapuche de Chile. No obstante, se trató de una opción metodológica, tanto para la optimización de recursos, como para establecer un aspecto del campo jurídico que facilite el estudio de su interacción con la identidad cultural indígena, ya que la jurisdicción penal ofrece "intensidades" y pone en evidencia las cuestiones más arraigadas del comportamiento judicial. Pero dicha decisión específica no es un impedimento epistemológico ni metodológico para el estudio y comparación de culturas jurídicas entrevistando actores jurídicos que se desempeñen en otros ámbitos jurisdiccionales. Por el contrario, el ejercicio presentado en este trabajo evidencia las oportunidades que ofrecen es-

${ }^{64}$ Las preguntas secundarias referidas fueron: ¿qué considera caracteriza la cultura jurídica de un determinado campo jurídico?, de acuerdo a cómo comprende la idea de cultura jurídica ¿qué actitudes o comportamiento considera caracterizan a los actores jurídicos del campo jurídico (brasileño/chileno)?; ¿ existe un derecho a la identidad cultural?, si considera que existe ¿quiénes serían titulares de ese derecho?, ¿es un derecho fundamental?; ¿cree que la identidad cultural de los pueblos indígenas de Brasil/Chile: es recogida, valorada y respetada en la cultura jurídica brasileña/chilena?

65 Se selccionó los entrevistados mediante una muestra amplia en relación a las distintas instituciones que componen el campo jurídico (en Chile): el Ministerio Público, el Poder Judicial, las Cortes de Apelaciones, la Defensoría Penal Pública, el Centro de Investigación y Defensa Sur (ONG Cidsur), Asociación Nacional de Magistrados (ANM)), para presentar la investigación y solicitar su colaboración. 
fuerzos metodológicos como el que aquí desplegamos, para el estudio de otros ámbitos del campo jurídico, la cultura jurídica y sus transformaciones. Estos estudios trascienden en causas y efectos la normatividad estrictamente positiva o el tipo de competencia o ámbito jurisdiccional que pueda tener un tribunal o actor jurídico. Por esta razón, considerando la advertencia precedente, la metodología presentada permite estudiar las transformaciones del Derecho (entendido como campo jurídico y su cultura jurídica) en diversos ámbitos de competencia material doméstica (penal, ambiental, constitucional) y en diversos niveles jurisdiccionales (nacionales, comparados o internacionales). Todo lo cual, reafirma esta metodología como una opción para el estudio del Derecho comparado y la cultura jurídica, en el marco regional americano. En este sentido, si entendemos el derecho fundamental a la identidad cultural de los pueblos indígenas y otros grupos vulnerables -como filtro hermenéutico-, conforme los respectivos dispositivos del Derecho Internacional de los derechos humanos y de las constituciones de Chile y Brasil, una misma metodología para el estudio comparado de los campos jurídicos y sus culturas jurídicas, en los diversos niveles y materias, es totalmente razonable.

\section{Ensayo piloto de la propuesta metodológica en Brasil:}

En la segunda fase de la investigación comparativa de culturas jurídicas, en el campo jurídico brasileño, se aplicó la metodología propuesta y desarrollada en la fase inicial chilena. Pero en este segundo campo jurídico, solo se aplicó de forma "piloto". En la segunda fase brasileña, la investigación tuvo los fines específicos de: (i) en cuanto al esfuerzo comparativo, visualizar transformaciones que pudieron ocurrir en el campo jurídico brasileño respecto del derecho a la identidad cultural, para hacer una comparación inicial de las respectivas culturas jurídicas con el campo jurídico chileno; (ii) metodológicamente, revisar la metodología propuesta, en sí y testearla cómo herramienta de estudio comparado, mediante su aplicación "piloto", en un número reducido de entrevistas a actores jurídicos claves en el nivel constitucional del campo jurídico brasileño. Considerando esta segunda finalidad metodológica, el trabajo de campo en Brasil fue acotado a un número reducido de entrevistas (complementadas y cotejada con información de fuentes secundarias, principalmente bibliográficas) y por ello, también, los resultados que se exponen son sintéticos.
Las entrevistas se realizaron a dos altos magistrados con competencia constitucional, a dos abogados asesores de una alta magistratura de competencia constitucional y a un periodista especializado en la cobertura judicial de los tribunales superiores de justicia brasileños. En todos los casos se usó la misma entrevista semiestructurada (diseñada y modelada en la investigación aplicada en Chile) que se adaptó al ámbito de desempeño del entrevistado y a sus requerimientos de reserva asociados a su cargo y a los tiempos disponibles. Las entrevistas fueron en lengua portuguesa, se tradujeron y se transcribieron profesionalmente de forma íntegra al español ${ }^{66}$ y se transcriben solo algunos aspectos relevantes para efectos comparativos.

\section{Investigación comparada en Chile y Brasil}

Conforme hemos descrito precedentemente, la comparación se realizará considerando: (1) los textos constitucionales, (2) el alcance que se ha dado a dichos textos por tribunales con competencia constitucional; (3) la cultura jurídica desde la percepción de los operadores jurídicos. Las dos primeras dimensiones se consideran como base positiva o normativa, para el estudio de la cultura jurídica, propiamente tal, en el tercer acercamiento. En todos los casos, el hilo conductor estará dado por el derecho fundamental a la identidad cultural.

\subsection{Cultura jurídica y dimensión positiva constitucional}

\section{Constitución Federal de Brasil de 1988:}

Artículo 231:

Se les reconocen a los indígenas su organización
social, costumbres, idiomas, creencias y tradiciones,
y sus derechos originales sobre las tierras que
tradicionalmente ocupan, y corresponde a la

66 Las entrevistas fueron realizadas por el co-investigador del proyecto y co-autor de este trabajo, Juan Jorge Faundes en Brasilia en el mes de abril de 2019.

Todos los entrevistados fueron grabados, en los audios consta el respectivo consentimiento de los entrevistados y el acuerdo de reservar su identidad, por lo que serán identificados conforme sus tareas como operadores en el sistema judicial brasileño ("juez tribunal superior 1", "juez tribunal superior 2", "abogado asesor 1", "abogado asesor 2" y "periodista". En total las grabaciones alcanzan aproximadamente a cuatro horas y media de entrevistas. 
Unión demarcar, proteger y hacer cumplir todas sus propiedades. $\int 1^{\circ}$ Son tierras tradicionalmente ocupadas por los indios aquellas habitadas permanentemente por ellos, las utilizadas para sus actividades productivas, las indispensables para la preservación de los recursos ambientales necesarios para su bienestar y las necesarias para su reproducción física y cultural, de acuerdo con sus usos, costumbres y tradiciones. $\int 2^{\circ}$ Las tierras tradicionalmente ocupadas por los indios están destinadas a su posesión permanente y al uso exclusivo de las riquezas del suelo, los ríos y los lagos en ellas. $\int 3^{\circ} \mathrm{El}$ uso de los recursos hídricos, incluidos los potenciales energéticos, la investigación y la extracción de riqueza mineral en tierras indígenas solo puede llevarse a cabo con la autorización del Congreso Nacional, previa consulta con las comunidades afectadas y su participación en los resultados del proceso minero está asegurada, en la forma de la ley. $\int 4^{\circ}$ Las tierras a las que se refiere este artículo son inalienables y no disponibles, y los derechos sobre ellas son imprescriptibles [...] (traducción libre).

Artículo 68:

"A los descendentes ["remanescentes"] de las comunidades de los quilombos que estén ocupando sus tierras, se reconocerá la propiedad definitiva, debiendo el Estado emitirles los respectivos títulos" ${ }^{\prime 67}$ (traducción libre).

\section{Constitución Política de Chile de 1980:}

En el caso chileno no existe una disposición constitucional de reconocimiento de los pueblos indígenas, ni de otros grupos minoritarios. Con todo, el reconocimiento sí se puede sostener a partir de la hermenéutica constitucional desarrollada por los tribunales con competencia constitucional -como veremos-. En este sentido, a lo menos, son relevantes los siguientes dispositivos de la Constitución Chilena:

Artículo1:

Las personas nacen libres e iguales en dignidad y derechos $[\ldots]$

El Estado está al servicio de la persona humana y su finalidad es promover el bien común, para lo cual debe contribuir a crear las condiciones sociales que permitan a todos y a cada uno de los integrantes de la comunidad nacional su mayor realización espiritual y material posible, con pleno respeto a los derechos y garantías que esta Constitución establece.

Es deber del Estado..., promover la integración

67 La Constitución de 1988 al decir "remanescentes" refiere a los actuales integrantes de los quilombos, en un sentido antropológico, como los "descendientes" de las comunidades quilombolas que, de una u otra forma, mantuvieron, su modo de vida tradicional hasta hoy. armónica de todos los sectores de la Nación y asegurar el derecho de las personas a participar con igualdad de oportunidades en la vida nacional".

Artículo19:

La Constitución asegura a todas las personas: $2^{\circ}$. "La igualdad ante la ley..."

Artículo 5 inc. 2:

El ejercicio de la soberanía reconoce como limitación el respeto a los derechos esenciales que emanan de la naturaleza humana. Es deber de los órganos del Estado respetar y promover tales derechos, garantizados por esta Constitución, así como por los tratados internacionales ratificados por Chile y que se encuentren vigentes."

Examinando los textos, la comparación estrictamente positiva no resultaría posible, porque, como vimos, disposiciones constitucionales expresas de reconocimiento solo las encontramos en el caso de la Constitución de Brasil de 1988. Ahora bien, en perspectiva hermenéutica, la comparación sí es posible, considerando, para el caso chileno el artículo 5 inc. $2^{\circ}$ de la Constitución chilena de 1980 que contiene una cláusula de reenvío a los tratados internacionales de derechos humanos ${ }^{68}$. Desde esa perspectiva, la jurisprudencia chilena ha entendido que el bloque de constitucionalidad chileno incluye los derechos a los pueblos indígenas y

68 En esta materia, aunque no será objeto de comparación, la Constitución Federal de 1988 contempla la incorporación de los tratados internacionales en materia de derechos humanos (art. 5 párr. 2 y 3), pero la jerarquía de esa incorporación a sido también materia de desarrollo jurisprudencial. Con todo, la incorporación interna de los tratados de derechos humanos no tiene la misma relevancia que en Chile, porque el reconocimiento constitucional brasileño es expreso y extenso. En relación con los tratados de derechos humanos, señala CAMPOS MELLO que el STF, originalmente, reconoció a los tratados sobre derechos humanos el estatus de ley ordinaria, otorgándoles -por tanto- el mismo tratamiento que a los demás tratados internacionales. Solo em 2009, el STF alteró su jurisprudencia, para reconocer a los tratados de derechos humanos estatus supralegal. Con la reforma constitucional n. 45/2004, que introduce el art. $5^{\circ}$, par. $3^{\circ}$, de la Constitución, al disponer de un proceso legislativo para la incorporación de tratados internacionales de derechos humanos, similar al aplicable a las enmiendas constitucionales, estos tratados alcanzaron el estatus constitucional. Explica que recién en 2009 los tratados internacionales fueron dotados de un status diferenciado de la ley ordinaria: "con el reconocimiento de un estatus supralegal a tales tratados, ellos pasaron a constituir un constituir un bloque se supralegalidad", que funciona como paradigma de control y como filtro hermenéutico" que impide la eficacia de las normas en conflicto o la interpretación conforme a los tratados. MELLO, PERRONE, Patrícia. Constitucionalismo, transformação e resiliência democrática no Brasil: o Ius Constitucionale Commune na América Latina tem uma contribuição a oferecer? Revista Brasileira de Políticas Públicas, Brasília, v. 9, n. 2, p.253-285, 2019. p. 271-272. 
en un plano jerárquico a lo menos equivalente a la Constitución ${ }^{69}$. Al efecto, a continuación, pasaremos a revisar sucintamente cómo se han interpretado, respectivamente, las constituciones de 1988 (Brasil) y la Constitución de 1980 (Chile).

\subsection{Dimensión normativa hermenéutica}

\section{Precedentes del Supremo Tribunal Federal de Brasil:}

En el campo jurídico brasileño, en relación con derechos de pueblos indígenas y otros grupos vulnerables, particularmente sobre el derecho a la identidad cultural, haremos referencia a la sentencia del caso Caso raposa serra do sol (STF) por ser el primer presente que desarrolló el contenido de la norma constitucional en relación al reconocimiento de los pueblos indígenas en $\mathrm{Brasil}^{70}$. Después sintetizamos otros precedentes relevantes para dar cuenta de la cultura constitucional en relación al derecho a la identidad cultural.

Dijo el STF en el Caso raposa serra do sol:

Áreas indígenas são demarcadas para servir concretamente de habitação permanente dos índios de uma determinada etnia, de par com as terras utilizadas para suas atividades produtivas, mais as "imprescindíveis à preservação dos recursos ambientais necessários a seu bem-estar" e ainda aquelas que se revelarem "necessárias à reprodução física e cultural" de cada qual das comunidades étnico-indígenas, "segundo seus usos, costumes e tradições" (usos, costumes e tradições deles, indígenas, e não usos, costumes e tradições dos não-índios). Terra indígena, no imaginário coletivo aborígine, não é um simples objeto de direito, mas ganha a dimensão de verdadeiro ente ou ser que resume em si toda ancestralidade, toda coetaneidade e toda posteridade de uma etnia. (p. 236)

Os direitos dos indios sobre as terras que tradicionalmente ocupam foram constitucionalmente "reconhecidos", e não simplesmente outorgados, com o que o ato de demarcação se orna de natureza declaratória, e não propriamente constitutiva". (p. 237)

[...] a traduzir um direito mais antigo do que qualquer outro, de maneira a preponderar sobre pretensos direitos adquiridos, mesmo os materializados em escrituras públicas ou títulos de legitimação de

\footnotetext{
${ }^{69}$ FAUNDES, Juan Jorge. Convenio N 169 de la OIT en la Jurisprudencia de la Excelentísima Corte Suprema en Chile. Tendencias y debates en materia de propiedad y derecho al Territorio. En Colecciones Jurídicas de la Corte Suprema, 2015. AYLWIN, José; MEZALOPEHANDÍA, Matías; YAÑEZ, Nancy. Los pueblos indígenas y el derecho. Santiago: LOM, Observatorio Ciudadano, 2013.

70 v. BRASIL. Supremo Tribunal Federal. Ação popular, Petição $n^{\circ}$ 3.388. Relator: Ministro Ayres Britto. Brasília, 19 de março de 2009.
}

posse em favor de não-índios. Atos, estes, que a própria Constituição declarou como "nulos e extintos. (p. 237)

[...] Donde a proibição constitucional de se remover os índios das terras por eles tradicionalmente ocupadas, assim como o reconhecimento do direito a uma posse permanente e usufruto exclusivo, de parelha com a regra de que todas essas terras "são inalienáveis e indisponíveis, e os direitos sobre elas, imprescritíveis. (p. 236)

\section{Análisis de los precedentes en el campo jurídico brasileño:}

Desde la visión del STF (Caso Raposa serra do sol) la Constitución de 1988 aseguró a los pueblos indígenas el derecho sobre las tierras que tradicionalmente ocupan (art. 231, CF/1988). Definió, como tierras tradicionalmente ocupadas, aquellas por ellos habitadas en carácter permanente, las utilizadas para sus actividades productivas, las imprescindibles para la preservación de los recursos ambientales necesarios para su bienestar y "as necessárias à sua reprodução física e cultural, segundo seus usos, costumes e tradições” (art. 231, $\$ 1^{\circ}$, CF/1988). Agregó que la tradicionalidad se refiere: al modo de ocupación de la tierra, a la identidad colectiva de cada etnia y a su cosmovisión. Que tiene relación con determinada forma de estar em el mundo y con su preservación, inclusive en perspectiva inmaterial y espiritual. Esta tradicionalidad se conecta con el deber del Estado de proteger sus formas "de expressão, sus modos de criar, fazer e viver, as produções artísticas, científicas e os espaços referentes a um grupo formador da sociedade brasileira (arts. 215 y 216, CF / 1988) ". Asimismo, en relación con el régimen constitucional de tutela de los pueblos indígenas, la "tradicionalidad" (tradicionalidade), constitucionalmente, fue caracterizada por el STF como la posesión originaria, de carácter permanente, marcada por un sentido de continuidad etnográfica y por una relación particular de los pueblos indígenas con la tierra, ligada a su subsistencia y a la preservación de sus costumbres y ritos ${ }^{71}$.

Además, con posterioridad el STF dictó diversos fallos en casos de comunidades quilombolas y sobre constitucionalidad de sacrificios de animales en el ámbito religioso, ampliando su comprensión del derecho a la identidad cultural en el texto constitucional de 1988. En estos casos, siguiendo a Campos Mello y

RASIL. Supremo Tribunal Federal. Ação popular, Petição nº 3.388. Relator: Ministro Ayres Britto. Brasília, 19 de março de 2009. 
Lacerda Accioly ${ }^{72}$, las comunidades quilombolas, compuestas por descendientes de antiguos esclavos fugitivos ("remanescentes"), que mantuvieron un modo de vida tradicional ${ }^{73}$, el STF concluyó que el criterio de la autoatribución era constitucional, conforme el Convenio $\mathrm{N}^{\circ} 169$ de la OIT (artículo $1 \mathrm{~N}^{\circ}$ 2) que reconocía la "conciencia de la propia identidad" como elemento base para establecer los mecanismos de protección de los grupos tradicionales. Asimismo, manifestó la necesidad de comprobación histórica del elemento objetivo de la ocupación tradicional y antropológica de la conexión de la comunidad con un viejo quilombo. El STF declaró constitucional la obligación de proteger la tierra de estas comunidades (inclusiva de todas las áreas necesarias para la "reproducción física, social, económica y cultural" de estas comunidades) e hizo presente que estas garantías fortalecían la identidad cultural de las comunidades quilombolas y su propia preservación. Por último, el STF reconoció la titulación colectiva de la tierra los quilombos ${ }^{74}$ como comunidad tradicional, aplicando analógicamente el criterio de reconocimiento de un estatus de protección constitucional ("heterodoxo") aplicado sobre tierras de los pueblos indígenas, en el caso Raposa Serra do Sol (Pet 3.388).

El Supremo Tribunal Federal, en sus precedentes sobre casos de sacrificios de animales por miembros de religiones de matriz africana ${ }^{75}$, rechazó la idea de un trato cruel a los animales. Observó que las prácticas religiosas que estaban siendo cuestionadas constituían "patrimonio cultural inmaterial" ${ }^{76}$ y que correspondían

72 v. CAMPOS MELLO, PERRONE, Patricia, LACERDA ACCIOLY, Clara. El derecho fundamental a la identidad cultural y el constitucionalismo en red en la jurisprudencia del supremo tribunal federal de Brasil. En: FAUNDES Juan Jorge; RAMÍREZ Silvina (Edts.). Derecho fundamental a la identidad cultural, abordajes plurales desde América Latina. Santiago: Universidad Autónoma de Chile, 2019 (en prensa). 73 Acción directa de inconstitucionalidad del Decreto №4.887/2003 del presidente de la República, que estableció un procedimiento de demarcación de las tierras ocupadas por comunidades quilombolas, en cumplimiento al art. 68 de las Disposiciones Constitucionales Transicionales ("Ato das Disposições Constitucionais Transitórias" o ADCT). Supremo Tribunal Federal, ADI 3239, 2018. 74 quilombos son las agrupaciones de esclavos fugitivos del período colonial e imperial de Brasil y también sus asentamientos (originariamente refugios frente a la persecución colonial). Las actuales comunidades quilombolas son consideradas pueblos tradicionales, descendientes de dichos quilombos. Aunque no son originarios, como los indígenas, cuentan con "rasgos étnico-culturales marcados por una relación sociocultural especial con la tierra ocupada” (Supremo Tribunal Federal, ADI 3239, 2018, p. 108).

75 BRASIL. Supremo Tribunal Federal. RE 494.601, 2019.

76 Artículo 2.2 c, Convención para la Salvaguardia del Patrimonio a las "formas de ser, hacer y vivir en varias comunidades religiosas y se confunden con la propia expresión de su identidad". Especificó que al constituir manifestaciones populares afrobrasileñas debían ser protegidas, porque se trata de una cultura históricamente estigmatizada (vulnerable), que ha sufrido racismo estructural, y que la protección especialmente otorgada en base a dicha condición no violaba la igualdad constitucional ${ }^{77}$.

Respecto de los instrumentos internacionales de derechos humanos, el STF fundamentó su decisión en las decisiones que impone el Convenio No169 de la OIT. Asimismo, en su decisión de mayoría, por una parte, siguió el fallo de la Corte IDH en el caso Mayagna (Sumo) Awas Tingui (referida en el Caso Raposa Serra do Sol), en relación a la falta de garantías del Estado en la obligación de demarcar y proteger la propiedad de los pueblos tradicionales. Y, por otra, justificó su sentencia en las decisiones de los casos Moiwana v. Suriname (2005) y Saramaka v. Suriname (2007) de la Corte IDH, en las cuales reconoció el derecho de propiedad y a los recursos naturales indispensables para su subsistencia, de la comunidad descendente de los marrones (esclavos fugitivos) sobre las tierras tradicionales que ocupan y o con las que mantenían relaciones territoriales específicas ${ }^{78}$.

En relación a la Constitución de 1988, desde la idea de "patrimonio cultural", se otorgó protección a los bienes y valores que se vinculen con "la identidad, la acción, la memoria de los diferentes grupos que forman la sociedad brasileña", incluyendo sus "formas de expresión”, sus “formas de crear, hacer y vivir", sus obras, objetos y "sitios de valor histórico, paisajístico, artístico,

Cultural Inmaterial de la Unesco.

77 v. CAMPOS MELLO, PERRONE, Patricia, LACERDA ACCIOLY, Clara. El derecho fundamental a la identidad cultural y el constitucionalismo en red en la jurisprudencia del supremo tribunal federal de Brasil. En: FAUNDES Juan Jorge; RAMÍREZ Silvina (eds.). Derecho fundamental a la identidad cultural, abordajes plurales desde América Latina. Santiago: Universidad Autónoma de Chile, 2019 (en prensa). v.: BRASIL. Supremo Tribunal Federal, ADI 3239. Rel. p/ acórdão: Min. Rosa Weber, j. 08/02/2018; BRASIL. Supremo Tribunal Federal. ADI 4.983, Rel. Min. Marco Aurélio, j. 06/10/2016.

78 v. CAMPOS MELLO, PERRONE, Patricia, LACERDA ACCIOLY, Clara. El derecho fundamental a la identidad cultural y el constitucionalismo en red en la jurisprudencia del supremo tribunal federal de Brasil. En: FAUNDES Juan Jorge; RAMÍREZ Silvina (eds.). Derecho fundamental a la identidad cultural, abordajes plurales desde América Latina. Santiago: Universidad Autónoma de Chile, 2019 (en prensa). v.: BRASIL. Supremo Tribunal Federal. ADI 3239, Rel. p/ acórdão: Min. Rosa Weber, j. 08/02/2018; BRASIL. Supremo Tribunal Federal. ADI 4.983, Rel. Min. Marco Aurélio, j. 06/10/2016. 
arqueológico, paleontológico, ecológico y científico"79. Así, la Constitución actual marcó el avance a una comprensión más amplia y plural de la cultura, que incluye aspectos identitarios de grupos vulnerables. En especial, se otorgó un nivel de protección diferenciado a los pueblos indígenas y quilombolas, reconociendo su vínculo intrínseco y cultural con las tierras que tradicionalmente ocup base de su propia subsistencia.

\section{Precedentes de cortes con competencia constitu- cional en Chile:}

El primer fallo en Chile en que se aplicó el Convenio $\mathrm{N}^{\circ} 169$ de la OIT fue "Francisca Linconao con Forestal Palemo (2009). En este caso, una machi ${ }^{80}$ reclamó la tala ilegal de bosques y la destrucción de manantiales (menoko) que afectaban la espiritualidad de estos lugares sagrados y destruyeron hierbas medicinales (lawen) fundamentales para su actividad tradicional. Dijeron los jueces en este caso:

\section{[...] el artículo 5 inciso segundo del Código Político señala que el ejercicio de la soberanía tiene como límite el respeto a los derechos esenciales que emanan de la naturaleza humana y... es deber de los órganos del Estado respetar y promover tales derechos $[\ldots]$}

[...] especial atención deben tener los Estados en la protección y preservación de las tierras y culturas indígenas en todas sus manifestaciones [...]

[...] el Derecho a Vivir en un medio libre de contaminación para la actora se ha visto afectado, puesto que se vulnera la integridad física y psíquica de esa etnia, se agravia en su naturaleza humana y la calidad de vida y en la protección de sus sistemas de salud, puesto que el Menoko es un lugar, espacio cultural, que no debe ser molestado, sino que siempre protegido ${ }^{81}$.

Tribunal Constitucional, TC 2552-2013 ${ }^{82}$ :

SEXTO: el Tribunal ha validado los mecanismos

79 v. CAMPOS MELLO, PERRONE, Patricia, LACERDA ACCIOLY, Clara. El derecho fundamental a la identidad cultural y el constitucionalismo en red en la jurisprudencia del supremo tribunal federal de Brasil". En, FAUNDES Juan Jorge; RAMÍREZ Silvina (eds.). Derecho fundamental a la identidad cultural, abordajes plurales desde América Latina. Santiago: Universidad Autónoma de Chile, 2019 (en prensa).

v.: BRASIL. Supremo Tribunal Federal. ADI 3239, Rel. p/ acórdão: Min. Rosa Weber, j. 08/02/2018; Supremo Tribunal Federal, ADI 4.983, Rel. Min. Marco Aurélio, j. 06/10/2016.

80 Autoridad tradicional del Pueblo Mapuche en el ámbito de la salud.

81 CHILE. Corte Apelaciones Temuco. Rol 1773-2008, 16 sep. 2009. Confirmada, Corte Suprema, Rol 7287-2009, 30 nov. 2009, Cons. $3^{\circ}, 4^{\circ}, 13^{\circ}$.

82 CHILE. Tribunal Constitucional. Rol 2552-2013, 24 dic. 2015. de afirmación positiva que establece el legislador. Estos son sistemas destinados a proteger a determinados grupos o sectores de personas que han sido históricamente minusvalorados. Son mecanismos cuyo propósito es asegurar la efectiva igualdad ante la ley... Estas medidas buscan que las personas tengan las mismas oportunidades en el punto de partida (articulo $1^{\circ}$ inciso final, de la Constitución) [...]

Este Tribunal ha [considera] que los indígenas [son] un grupo "socio-económicamente vulnerable, con la especificidad histórica cultural que le es propia";

SÉPTIMO: [...] la Constitución no establece un tipo de propiedad determinada. Reconoce la propiedad 'en sus diversas especies'. No hay una sola propiedad, sino tantas propiedades como el legislador configure. No existe una propiedad general y propiedades especiales; existen sólo propiedades distintas, con estatutos propios. No hay en la Constitución un modelo a partir del cual se construyan las distintas propiedades".

OCTAVO: [...] no solamente hay normas nacionales que el Estado de Chile debe respetar, sino tratados internacionales. Uno de ellos es el Convenio $\mathrm{N}^{\circ}$ 169, sobre Pueblos Indígenas y Tribales... En este sentido, el Convenio establece que 'deberán adoptarse las medidas especiales que se precisen para salvaguardar las personas, las instituciones, los bienes, el trabajo, las culturas y el medio ambiente de los pueblos interesados ${ }^{83}$.

Finalmente, en el marco de una extensa jurisprudencia desarrollada por los tribunales superiores chilenos (2009-2020) ${ }^{84}$, la Corte Suprema de Chile da cuenta de la comprensión constitucional en relación al derecho a la identidad cultural de los pueblos indígenas en dos casos que revisamos sintéticamente:

(i) En el caso del Cerro Ceremonial Topater, señaló el máximo tribunal de Chile que el proyecto impugnado perturbó "el derecho legítimo que tienen las recurrentes, tanto al libre ejercicio y desarrollo de sus creencias religiosas y ritos sagrados, garantido para ellas y sus con-

83 En los párrafos siguientes transcribe íntegramente los artículos 14 y 15 del convenio en relación con las tierras de uso tradicional de los pueblos indígenas y el derecho a los recursos naturales que existen en sus territorios."

${ }^{84}$ AYLWIN, José; MEZA-LOPEHANDÍA, Matías; YAÑEZ, Nancy. Los pueblos indigenas y el derecho. Santiago: LOM, Observatorio Ciudadano, 2013. FAUNDES, Juan Jorge. Convenio n.169 de la OIT en la Jurisprudencia de la Excelentísima Corte Suprema en Chile. Tendencias y debates en materia de propiedad y derecho al Territorio. En Colecciones Jurídicas de la Corte Suprema, 2015. FAUNDES, Juan Jorge. El derecho fundamental a la identidad cultural de los pueblos indígenas, configuración conforme el derecho internacional y perspectivas de su recepción en Chile. Revista Ius et Praxis, n.1, 2020. 
géneres [art. $19 \mathrm{~N}^{\circ} 6$ de la Constitución] de modo que, de tolerar que se los pase a llevar, se los diferenciaría, arbitrariamente". Y... que los actos recurridos contrarían "la garantía de igualdad y no discriminación que sienta el numeral $2^{\circ}$ del propio artículo 19" ${ }^{\prime 35}$. (ii) En el caso de Remingual Lemui Cristobal con Ilustre Municipalidad de Osorno, señaló que el uso no consentido de la imagen (fotografía) de un machi en un calendario municipal afectó al requirente "por el menoscabo a su credibilidad como autoridad del pueblo originario al que pertenece, teniendo en consideración además, que su imagen es publicada en un contexto de tradiciones chilenas, no obstante que su condición de machi se contextualiza dentro de la cultura y creencias del pueblo mapuche". ${ }^{86}$

\section{Análisis de los precedentes en el campo jurídico chileno:}

Como se constató, la Constitución Política de Chile (CPR) no contempla en su texto ni el derecho a la identidad -genéricamente-, ni los derechos culturales, para pueblos indígenas u otros grupos. De esta forma, el reconocimiento y protección constitucional del derecho fundamental a la identidad cultural, supone un ejercicio de interpretación, en relación con los instrumentos internacionales en materia de derechos humanos que contemplan los derechos de los pueblos indígenas, en relación, asimismo, con otros derechos fundamentales contemplados en la Carta Fundamental. Así, constitucionalmente, el derecho a la identidad cultural se fundó en una visión amplia del principio de igualdad y del respeto de la dignidad humana ${ }^{87}$, de conformidad con el artículo 1 inc. $1^{\circ}$ de la Constitución Chilena que establece que es deber del Estado "asegurar el derecho de las personas a participar con igualdad de oportunidades en la vida nacional" y (inc. Final art. 1 de la Constitución) el derecho a "intervenir con igualdad de condiciones a su mayor realización espiritual y material posible”. Todo, en relación al artículo 19 que asegura a todas las personas ( $\left.{ }^{\circ} 2\right)$ "La igualdad ante la ley", $\left(\mathrm{N}^{\circ} 4\right)$ el derecho a la vida privada y la honra de la persona y la familia, $\left(\mathrm{N}^{\circ} 6\right)$ la libertad de creencias y de religión, $\left(\mathrm{N}^{\circ} 8\right)$ el derecho a vivir en un medio ambiente libre de contaminación

\footnotetext{
85 CHILE. Corte Suprema. Rol 3010-2013, 26 sep. 2013; CHILE. Corte Apelaciones Valdivia. Rol 501-2011; (revoca) Corte suprema, Rol 3.863-2012.

86 Corte Apelaciones Valdivia, Rol 651-2012, 7 dic. 2012; Corte Suprema, Rol 481-2013, 23 sep. 2013.

87 CHILE. Corte Apelaciones de Temuco. Rol 1773-2008, 16 sep.2009; Corte Suprema, Rol 7287-2009, 30 nov. 2009, Cons. $4^{\circ}$ y $13^{\circ}$.
}

y $\left(\mathrm{N}^{\circ} 24\right)$ el derecho de propiedad ${ }^{88}$, entre otros. Conforme con ello, la protección del derecho a la identidad cultural de los pueblos indígenas, sus comunidades y miembros, suponen un ejercicio hermenéutico de cortes con competencia constitucional.

Conjuntamente, de conformidad al artículo 5 inciso $2^{\circ}$ de la Constitución, la jurisprudencia chilena ha reconocido en sus fallos el derecho a la identidad cultural de los pueblos indígenas, con diversos alcances, invocando el Convenio 169 de la OIT, como tratado internacional de derechos humanos vigente en el país ${ }^{89}$.

Por su parte, el Tribunal Constitucional admite la existencia de estatutos o normativas especiales, en perspectiva afirmativa para la protección de grupos vulnerables. Para él, en particular, el derecho a la identidad cultural se vincula hermenéuticamente con otros derechos fundamentales, tales como la protección del medio ambiente y el hábitat de estos pueblos, el derecho de propiedad en relación a sus tierras, territorios y recursos

\subsection{Estudio de la cultura jurídica en los campos jurídicos de Brasil y Chile}

\subsubsection{La Cultura jurídica chilena y contexto en relación al derecho a la identidad cultural:}

En el campo jurídico chileno imperan un Derecho "monista-positivista". Pero, al mismo tiempo, el ordenamiento jurídico, desde sus propias definiciones constitucionales, se encuentra abierto a la incorporación del Derecho Internacional de los Derechos Humanos, lo que ha generado una presión inductora de un proceso inicial de transformación. Por ello, sobre la caracterización de la cultura chilena, en general, podemos abordarla desde dos perspectivas: (i) desde la sostenida apertura al Derecho Internacional de los derechos humanos, con un especial desarrollo en el caso de los derechos indí-

\footnotetext{
88 Una descripción del desarrollo hermenéutico del derecho fundamental a la identidad cultural de los tribunales chilenos con competencia constitucional v. FAUNDES, Juan Jorge, El derecho fundamental a la identidad cultural de los pueblos indígenas, configuración conforme el derecho internacional y perspectivas de su recepción en Chile. Revista Ius et Praxis, n. 1, 2020.

89 CHILE. Corte Suprema, Rol 7287-2009, 30 nov. 2009; Corte Suprema Rol 2840-2008, 25 nov. 2009; Corte Suprema, Rol 10.0902011, 22 marzo 2012. En la misma línea los fallos: Tribunal Constitucional, Rol 2387-2012, 23 en.2013; Tribunal Constitucional, Rol 2552-2013, 24 dic. 2015
} 
genas; (ii) desde las prácticas y la toma de decisiones de los jueces, en relación al derecho a la identidad cultural de los pueblos indígenas.

Desde la recepción del Derecho Internacional de los derechos humanos, Chile, superando diversas condenas por vulneración de la $\mathrm{CADH}$, ha realizado esfuerzos para el cumplimiento de las decisiones de la Corte IDH bajo la doctrina del Control de Convencionalidad ${ }^{90}$, mayoritariamente internalizado por los jueces. En este sentido, el constitucionalismo chileno se enmarca dentro de las visiones que Mariela Morales llama de la "estatalidad abierta" "91, que suponen, a lo menos, el diálogo entre los sistemas derechos humanos, de los tribunales regionales de derechos humanos con las cortes nacionales. Comparten la necesidad de fortalecer la protección de la persona y los derechos de grupos vulnerables desde el desarrollo de mayores estándares regionales en materia de derechos humanos ${ }^{92}$. En particular, este desarrollo normativo ha llevado a afirmar la existencia de un corpus iuris de derechos de los pueblos indígenas ${ }^{93}$. Este enfoque se evidenció con las sentencias revisadas precedentemente.

Por otra parte, en Chile, el inicio de un nuevo ciclo reivindicativo indígena, al comienzo de los años 90, diversas organizaciones mapuche plantearon un conjunto de demandas de derechos de los pueblos indígenas que fue el punto de partida para un sostenido proceso de reconocimiento de derechos. Por su parte, los jueces en las diversas competencias y niveles jurisdiccionales, han venido dando respuesta a las demandas indígenas. Sin embargo, el proceso evolutivo de reconocimiento de derechos que se observa es complejo, ya que se encuentra cruzado por disputas y frecuentes críticas hacia el sistema judicial por la "permisibilidad" y el apoyo a

\footnotetext{
90 v. HENRÍQUEZ, Miriam; MORALES, Mariela. El control de convencionalidad: un balance comparado a 10 años de Almonacid Arellano vs. Chile. Santiago: DER Ediciones, 2017.

91 MORALES ANTONIAZZI, Mariela. O Estado Aberto: Objetivo do Ius Constitucionale Commune. En: BOGDANDY, Armin von, MORALES ANTONIAZZI, Mariela, PIOVESAN, Flávia (coord). Ius Constitucionale Commune na América Latina: marco conceptual. Curitiba: Juruá, 2016. v. 1. p. 53-74.

92 FAUNDES, Juan Jorge, "El derecho fundamental a la identidad cultural de los pueblos indígenas: un derecho matriz y filtro hermenéutico para las constituciones de América Latina: la justificación”. Revista Brasileira Politicas Públicas, v. 2, n. 2. p. 513-535, ago. 2019.

93 AYLWIN, José; MEZA-LOPEHANDÍA, Matías; YAÑEZ, Nancy. Los pueblos indigenas y el derecho. Santiago: LOM, Observatorio Ciudadano, 2013.
}

las lógicas privadas inversoras. Por ejemplo, encontramos un desarrollo jurisprudencial relevante en materia de propiedad, cruzado por conflictos entre intereses de privados y comunidades indígenas, con conflictos por la ocupación tradicional, la propiedad colectiva, respecto de las lógicas preponderantes de la propiedad registral; también hay conflictos en materia de consulta indígena y proyectos de inversión con efectos ambientales; o bien, en materia de "justicia indígena", donde se demanda el derecho a la resolución de conflictos reconociendo las formas tradicionales indígenas, su derecho propio y o con intervención de autoridades tradicionales indígenas.

Particularmente, muchos de los debates enunciados ocurrieron en paralelo a la llamada "Reforma a la Justicia", en especial en el campo penal y tuvieron efectos no solo en la gestión judicial, sino que en materia de derechos humanos y de derechos de los pueblos indígenas ${ }^{94}$. Entre otros aspectos, se puede destacar, la invocación, cada vez más frecuente, de la "defensa cultural" en los tribunales penales, en particular de parte de abogados especializados, perteneciente a la Defensoría Penal Pública que están apoyados por facilitadores interculturale o la intervención como expertos de autoridades tradicionales indígenas y de peritos antropólogos en causas judiciales ${ }^{96}$.

En el marco de los avances y tensiones indicados, en una visión crítica a la gestión del sistema judicial, Le Bonniec y Cloud señalan:

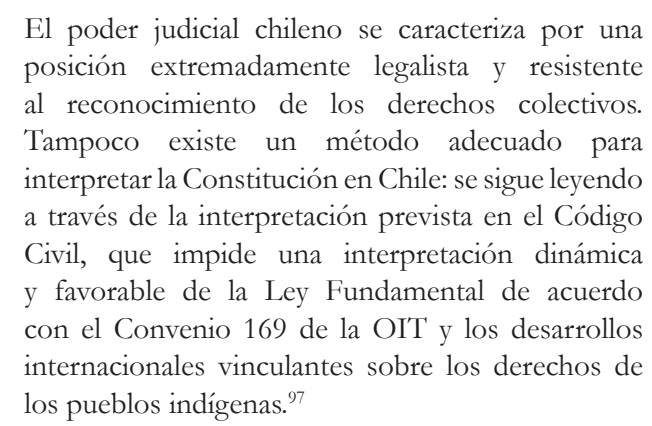

${ }^{94}$ CENTRO DE ESTUDIOS DE JUSTICIA DE LAS AMÉRICAS. Reforma procesal penal y pueblos indígenas, 2015.

95 COUSO, Javier. Mapuches y Derecho Penal. In: OLEA RODRÍGUEZ, HELENA (ed). Derecho y Pueblo Mapuche: aportes para la discusión. Santiago: Centro de Derechos Humanos UDP, 2013. p. 155-214; LILLO. LE BONNIEC, Fabien. Juridicité autochtone et différence culturelle. Ethnologie française, v. 169, n. 1, p. 141, 2018.

96 BERHO, Marcelo; CASTRO, Paulo; LE BONNIEC, Fabien. La Pericia Antropológica En La Araucanía de Chile. Entre Teorías Y Prácticas, 2003 - 2014. Antropologías Del Sur, v. 16, n. 3, p. 107-126, 2018.

97 CLOUD, Leslie; LE BONNIEC, Fabien. Dynamiques actuelles de criminalisation et de judiciarisation des droits autochtones au 
Con todo, en materia de acceso a la justicia, podemos referir a la suscripción por parte de la Corte Suprema del "Protocolo Iberoamericano de actuación judicial para mejorar el acceso a la justicia de personas, comunidades y pueblos indígenas"98; y, más recientemente, la adhesión de la Asociación Nacional de Magistrados a un protocolo de atención a usuarios y usuarias mapuche en los tribunales y juzgados de la Macrorregion Sur (Pau-Mapu $)^{99}$. Así, por una parte, en Chile se puede observar una resistencia a llevar procesos de cambios constitucionales ${ }^{100}$, como una judicatura poco propicia a producir una jurisprudencia favorable al reconocimiento de los derechos indígenas ${ }^{101}$. Con sus más altos tribunales y cortes, muy formalistas ${ }^{102}$, que han tenido una tendencia a pronunciarse de forma "excesivamente deferente con los poderes políticos" ${ }^{\prime 103}$.

No obstante, a pesar de esta resistencia y de la ausencia de un marco constitucional progresista, diversos fallos, han venido admitiendo la emergencia de nuevos actores, lo que sugiere una permeabilidad emergente del monoculturalismo jurídico chileno a reconocer el derecho a la identidad cultural ${ }^{104}$ y la capacidad de sus

Chili. En: BELLIER, IRÈNE; HAYS, JENNIFER (org.). Echelles de gouvernance et peuples autochtones: de nouveaux droits ou la répétition des erreurs du passé ? Paris: L'Harmattan, 2019, p. 235-254. p. 250. 98 La Corte Suprema, como miembro de la XVII Cumbre Judicial Iberoamericana desarrollada en el año 2014 en Santiago de Chile, ha suscrito el Protocolo iberoamericano de actuación judicial para mejorar el acceso a la justicia de personas, comunidades y pueblos indígenas

99 Prensa UC Temuco» Asociación de Magistrados aprueba protocolo de atención elaborado por la UC Temuco. Disponible en: $<$ https://prensa.uct.cl/2019/10/asociacion-de-magistrados-aprueba-protocolo-de-atencion-elaborado-por-la-uc-temuco/>.

100 RODRÍGUEZ, César. Navegando la globalización: un mapamundi para el estudio y la práctica del derecho en América Latina. In: RODRÍGUEZ, CÉSAR (coord.). El derecho en América Latina: un mapa para el pensamiento jurídico del siglo XXI. Buenos Aires: Siglo XXI, 2011. p. 69-84.

101 CLOUD, L.; LE BONNIEC, F. The competing logics of the state and indigeneity: the dynamics of Mapuche territoriality in the context of indigenous peoples' right to self-determination. Quaderns de l'Institut Catala d'Antropologia, v. 17, n. 1, 2012.

102 COUSO, Javier; HILBINK, Lisa. From Quietism to Incipient Activism: The Institutional and Ideological Roots of Rights Adjudication in Chile. En: HELMKE, GRETCHEN; RÍOS-FIGUEROA, JULIO (eds.). Courts in Latin America. Cambridge: Cambridge University Press, 2011. p. 99-127.

103 POU, Francisca. Justicia constitucional y protección de derechos en América Latina: el debate sobre la regionalización del activismo. In: RODRÍGUEZ, CÉSAR (ed.). El derecho en América Latina: un mapa para el pensamiento jurídico del siglo XXI. Buenos Aires: Siglo XXI, 2011. p. 235.

104 LE BONNIEC, Fabien. Interrogantes en torno a la emergencia del peritaje antropológico en las cortes de justicia del sur de Chile. In: actores de contextualizar sus decisiones. Este reconocimiento inicial, principalmente jurisprudencial, está más bien localizado en las regiones de mayor concentración indígena (En el norte, Aymara y Quechua, y en la macro región sur, Mapuche). Este fenómeno deja aparecer un abanico de actores relevantes en los procesos de reconocimiento legal de prácticas asociadas al enunciado derecho fundamental a la identidad cultural.

\subsubsection{La Cultura jurídica brasileña y contexto en relación al derecho a la identidad cultural:}

Abordamos la contextualización de la cultura jurídica brasileira desde tres perspectivas: (i) en relación a las instituciones la "permeabilidad" del monismo jurídico y las nuevas perspectivas del derecho a la identidad cultural; (ii) en relación a la recepción limitada del Derecho Internacional de los derechos humanos; (iii) una perspectiva crítica al "patrimonialismo".

Desde un punto de vista constitucional, se observa una cierta dualidad, una tensión entre la apertura constitucional que se despliega con el texto de 1988 y las prácticas institucionales que muchos más lentas que el texto fundamental van dando cuenta de la valoración de la diversidad y del derecho a la identidad cultural. En ese sentido, las visiones de la cultura jurídica y la cultura constitucional, según en qué aspecto se centre la atención, son más o menos optimistas. Así, desde la mirada de los cambios normativos que introduce la Constitución de 1988, señalan Campos Mello y Lacerda Accioly que el fortalecimiento de la democracia brasileña fue esencial para iniciar un proceso de reconocimiento de la diversidad -contrario al estatus dominante- que ha significado una "resignificación del sentido del pueblo brasileño". Al respecto, señalan que la Constitución de 1988: permitió un giro en el alcance de la protección constitucional de la cultura; estableció el deber de las autoridades públicas de promover y proteger la cultura; determinó la responsabilidad del Estado en el deber de proporcionar a todos el acceso a la cultura; reconoció a la persona como quien produce cultura y como quien se beneficia de ella. En el mismo sentido señalan que la Constitución de 1988:

[...] alteró sustancialmente el sentido atribuido a la expresión 'patrimonio cultural', determinando la

CARRASCO, MORITA; LUXARDO, NATALIA (eds.). El orden cuestionado: lecturas de antropología jurídica. Buenos Aires: UNSAM Edita, 2018. p. 117-130. 
protección de los bienes que digan relación con 'la identidad, la acción, la memoria de los diferentes grupos que forman la sociedad brasileña', incluyendo sus 'ormas de expresión', sus 'formas de crear, hacer y vivir', sus obras, objetos y 'sitios de valor histórico, paisajístico, artístico, arqueológico, paleontológico, ecológico y científico'. ${ }^{105}$

De esta forma, concluyen que la Constitución brasileña de 1988 avanzó en una “comprensión más amplia y plural de la cultura, que incluye aspectos identitarios de grupos vulnerables". Y que, al mismo tiempo, se abandonaron las concepciones asimilacionistas y homogeneizantes en relación a estos grupos", para otorgar una protección diferenciada a los pueblos indígenas y quilombolas, "reconociendo su vínculo intrínseco y cultural con las tierras que tradicionalmente ocupan" ${ }^{106}$.

Mientras, desde la revisión de las prácticas de la cultura jurídica en Brasil, -entre otros: Roberto Lyra Filho, Luís Alberto Warat, Roberto Aguiar, Agostinho Ramalho Marques Neto, Antônio Carlos Wolkmer, José Eduardo Faria, Leonel Severo Rocha, Lênio Luiz Streck, José Luiz Bolzan), cuestionan los límites de la Teoría del derecho de matriz monista y formalista, todavía fuertemente basada en el monismo legal, caracterizado, por la estadidad, singularidad, positividad y racionalidad. Plantean que dicha cultura jurídica dificulta hacer frente a los desafíos de las nuevas configuraciones sociales y los conflictos emergentes de la diversidad cultural ${ }^{107}$.

105 v. CAMPOS MELLO PERRONE, Patrícia, LACERDA ACCIOLY, Clara. "El derecho fundamental a la identidad cultural y el constitucionalismo en red en la jurisprudencia del supremo tribunal federal de Brasil". En, FAUNDES Juan Jorge; RAMÍREZ Silvina (eds.). Derecho fundamental a la identidad cultural, abordajes plurales desde América Latina. Santiago: Universidad Autónoma de Chile, 2019 (en prensa).

v.: BRASIL. Supremo Tribunal Federal, ADI 3239, Rel. p/ acórdão: Min. Rosa Weber, j. 08/02/2018; BRASIL. Supremo Tribunal Federal, ADI 4.983, Rel. Min. Marco Aurélio, j. 06/10/2016.

106 v. CAMPOS MELLO PERRONE Patrícia, LACERDA ACCIOLY, Clara. El derecho fundamental a la identidad cultural y el constitucionalismo en red en la jurisprudencia del supremo tribunal federal de Brasil. En: FAUNDES Juan Jorge; RAMÍREZ Silvina (eds.). Derecho fundamental a la identidad cultural, abordajes plurales desde América Latina. Santiago: Universidad Autónoma de Chile, 2019 (en prensa). v.: BRASIL. Supremo Tribunal Federal. ADI 3239, Rel. p/ acórdão: Min. Rosa Weber, j. 08/02/2018; BRASIL. Supremo Tribunal Federal. ADI 4.983, Rel. Min. Marco Aurélio, j. 06/10/2016.

107 WINCKLER, Silvana Terezinha; CANZI, Idir; BRAUN, Helenice da Aparecida Dambrós. Direitos humanos e multietnicidade como desafios à Cultura jurídica brasileira. Revista Direitos Culturais, v.6. n. 11, 2011. p.6.

WINCKLER, Silvana Terezinha; CANZI, Idir; BRAUN, Helenice da Aparecida Dambrós. Direitos humanos e multietnicidade como desafios à Cultura jurídica brasileira. Revista Direitos Culturais, v.6. n.
Con todo, en la actualidad, dando cuenta del cambio normativo y de las tensiones en la cultura jurídica, por sobre las resistencias de la cultura jurídica occidental hegemónica, se visualiza el desgaste de sus fundamentos paradigmáticos, como la crisis de valores y desajustes institucionales lo que abriría espacios para construir un nuevo paradigma para la cultura jurídica y política ${ }^{108}$, comprensiva de la diversidad cultural y el derecho a la identidad cultural. Así, se afirma que el derecho a la identidad cultural, si bien, viene permeando lenta y progresivamente la cultura jurídica, aún se trata de "derechos en disputa", particularmente respecto de recursos naturales ${ }^{109}$.

Un segundo aspecto relevante de la cultura jurídica brasileña, especialmente en el ámbito constitucional, refiere a la protección internacional de los derechos humanos. Como pudimos revisar, el texto de la Constitución determinó de 1988 (art. $5^{\circ}$, par. $2^{\circ}$, más la adenda posterior del párrafo $3^{\circ}$ ), los derechos fundamentales contemplados en la Constitución comparten marco normativo constitucional con aquellos contemplados en los tratados internacionales sobre derechos humanos de los que el Brasil forma parte. En estos términos, la Constitución de Brasil de 1988 introdujo una cláusula de apertura al Derecho Internacional de los Derechos Humanos y estableció las bases para un diálogo entre los tribunales internacionales y los nacionales en materia de derechos humanos ${ }^{110}$.

En este sentido, se afirma que en Brasil existe una cultura jurídica más conservadora respecto de la in-

\section{1, 2011. p.1.}

108 WINCKLER, Silvana Terezinha; CANZI, Idir; BRAUN, Helenice da Aparecida Dambrós. Direitos humanos e multietnicidade como desafios à Cultura jurídica brasileira. Revista Direitos Culturais, v.6. n. 11, 2011. p.6.

109 Dice Verdum: "La eficacia de los derechos indígenas, terreno en disputa [...] -..En los últimos tres años [2016-2019], las normas relativas al reconocimiento de los derechos territoriales de los pueblos indígenas y de las comunidades tradicionales y las que regulan la creación y el uso de áreas protegidas, en particular de unidades de conservación (UCs) son el centro de la disputa de los pueblos indígenas con los grupos económico-políticos y financieros interesados en la flexibilización y revisión de esos derechos". VERDUM, Ricardo. La estrategia conservadora y neoliberal contra los derechos de los pueblos indígenas y comunidades tradicionales en Brasil. Debates indigenas, nov. 2019. p. 3-4. v. AMORIM, Fabrício, BURGER, Leila, RODRIGUES, Patrícia, ALCANTARA E SILVA, Victor. Silenced genocides: genocídios silenciados. São Paulo: Edited by: IWGIA/GAPK, 2019.

110 VARELLA, Marcelo. Internacionalização do direito: direito internacional, globalização e complexidade. Tese (Doutorando em Direito Internacional) - Faculdade de Direito, Universidade de São Paulo (USP), São Paulo, 2012. 
fluencia del Derecho Internacional de los Derechos Humanos, porque el uso de la jurisprudencia interamericana no sería una práctica internalizada en la argumentación de jueces y abogados ${ }^{111}$. Asimismo, que el control de convencionalidad no ha logrado instalarse como un mecanismo jurisdiccional que integre la que podríamos llamar "caja de herramientas" de los jueces ${ }^{112}$. Como dice Campos Mello los jueces no deciden en base a las normas de derechos humanos, "las decisiones de la Corte IDH siguen siendo un elemento 'extraño' y muy poco familiar para el conocimiento jurídico general”. Plantea que incluso la jurisprudencia es reacia a atribuir eficacia mayor a la ratio decidendi de las decisiones de la Corte IDH $^{113}$; y que la resistencia alcanza, hasta el cumplimiento de las sentencias de la Corte IDH dictadas contra Brasil que de ocho condenas, solo ha cumplido una decisión íntegramente ${ }^{114} \cdot{ }^{115}$

111 CAMPOS MELLO, PERRONE, Patrícia. Constitucionalismo, transformação e resiliência democrática no Brasil: o Ius Constitucionale Commune na América Latina tem uma contribuição a oferecer? Revista Brasileira de Políticas Públicas, v. 9, n. 2, p. 253-285, 2019. p. 271-272.

112 Sobre el control de convencionalidad interamericano en Brasil v. FACHIN, Melina Girardi; RIBAS, Ana Carolina; CAVASSIN, Lucas Carli. Perspectivas do controle de convencionalidade do sistema interamericano de direitos humanos no Brasil: implicações para um novo constitucionalismo. BOGDANDY, Armin von; ANTONIAZZI, Mariela Morales; PIOVESAN, Flávia (Coord). Ius Constitutionale Commune na América Latina: diálogos jurisdicionais e controle de convencionalidade. Curitiba: Juruá, 2016. v. 3. p. 295-297; MARINONI, Luiz Guilherme; MAZZUOLI, Valério de Oliveira. Apresentação. En: MARINONI, Luiz Guilherme; MAZZUOLI, Valério de Oliveira (org.). Controle de Convencionalidade: um panorama latino-americano. Brasília: Gazeta Jurídica, 2013. p. XIII-XV.

113 Por ejemplo, la acción directa de inconstitucionalidad sobre la validez de la Ley de Amnistía al régimen militar fue declarada improcedente (ADPF 153). La decisión se tomó contrariando los precedentes de la Corte IDH, incluso en oposición a la sentencia del Caso Gomes Lund v. Brasil (20109. CAMPOS MELLO, PERRONE, Patrícia. Constitucionalismo, transformação e resiliência democrática no Brasil: o Ius Constitucionale Commune na América Latina tem uma contribuição a oferecer? Revista Brasileira de Políticas Públicas, Brasília, v. 9, n. 2 p.253-285, 2019. p 273-274.

114 Corte IDH. Supervisão de Cumprimento de Sentença do Caso Escher e Outros vs. Brasil, 20 de febrero de 2012. Sentencias parcial o totalmente: Herzog y otros vs. Brasil, j. 15 de marzo de 2018; Caso Pueblo Indígena Xucuru vs. Brasil, j. 5 de febrero de 2018; Caso Trabajadores de la Fazenda Brasil Verde vs. Brasil, j. 20 de octubre de 2016; Supervisión de Cumplimiento de Sentencia de Favela Nova Brasília vs. Brasil, 30 de mayo de 2018; Supervisión de Cumplimiento de Sentencia de Garibaldi vs. Brasil, 22 de febrero de 2012; Supervisión de Cumplimiento de Sentencia de Ximenes Lopes vs. Brasil, j. 17 de mayo de 2010.

115 CAMPOS MELLO, PERRONE, Patrícia. Constitucionalismo, transformação e resiliência democrática no Brasil: o Ius Constitucionale Commune na América Latina tem uma contribuição a oferecer? Revista Brasileira de Políticas Públicas, Brasília, v. 9, n. 2 p.253-285,
En los apartados anteriores vimos la relativa permeabilidad que ha tenido la cultura jurídica brasileña en relación con el derecho a la identidad cultural en los precedentes revisados. Y más adelante lo cotejaremos con la percepción de los actores jurídicos entrevistados.

Una última cuestión el denominado "patrimonialismo" que -aunque se encuentra presente en diversos escenarios nacionales- tiene especial impacto en el caso de Brasil. Esta característica de la cultura jurídica (en interacción con la cultura general) habla de una confusión entre lo público y lo privado, al punto de una percepción de que el Estado existe para el servicio propio y de que las normas no se aplican en igualdad entre distintos grupos sociales, porque están mucho más apegadas al status del grupo a que uno pertenece. En este contexto, por ejemplo, es difícil reconocer derechos a las comunidades indígenas o tribales, porque colisionan con intereses de otros grupos de status más elevado/más próximos del poder. En estrecha relación con el "patrimonialismo" está "o jeitinho brasileiro"116 que tanto refiere a la alegría, al afecto cotidiano y a una suerte de resiliencia frente a la adversidad y desigualdad social del pueblo brasileño, como también contiene una caracterización de la cultura política y jurídica, crítica, que identifica una cultura jurídica que se basa en el contornar y acomodar las reglas o directamente violar la ley (como pedir al juez amigo flexibilidad), en vincular la ética privada con el comportamiento en la esfera pública, haciendo que decisiones que debían ser impersonales, se tornen personales, comprometiendo, finalmente, la aplicación igualitaria del derecho ${ }^{117}$. Como dice Luis Roberto Barroso:

Na sua acepção mais comum, jeitinho identifica
os comportamentos de um indivíduo voltados à
resolução de problemas por via informal, valendo-
se de diferentes recursos, que podem variar do uso
do charme e da simpatia até a corrupção pura e
simples. Em sua essência, o jeitinho envolve uma
pessoalização das relações, para o fim de criar regras

2019. p 273-274.

116 Para el lector en español se podría traducir como "el estilo brasileño", pero su alcance está lejos de agotarse en esta expresión hispana.

117 BARROSO, Luis Roberto. Ética e jeitinho brasileiro: por que a gente é assim. Ponencia presentada en la Brazil Conference, Universidad de Harvard, 2017. Consultor Jurídico, 10 abr. 2017. p. 5; Campos Mello 214-219. HOLANDA, Sergio Buarque de. Raizes do Brasil. Rio de Janeiro: José Olympio, 1991 (a $1^{\mathrm{a}}$ edição é de 1936); HOLANDA, Sérgio Buarque de. Raízes do Brasil. Op. cit., p. 134-148. SILVEIRA SIQUEIRA, Gustavo. Movimentos sociais e cultura jurídica brasileira. Revista Direitos Culturais, v. 5, n. 8, 2010. 
particulares para si, flexibilizando ou quebrando normas sociais ou legais que deveriam se aplicar a todos. Embutido no jeitinho, normalmente estará a tentativa de criar um vínculo afetivo ou emocional com o interlocutor. ${ }^{118}$

Estas prácticas constitutivas de la cultura jurídica brasileña se encontrarían arraigadas desde la propia historia de la colonización del país, siendo constitutivas de privilegios de arrastre histórico para ciertos grupos y familias, expandidas luego al ámbito público, caracterizadas por la protección oligarca patriarcal en desmedro de movimientos sociales populares ${ }^{119} \mathrm{y}$, en particular, de grupos vulnerables. En todos estos casos de "patrimonialismo" y del "jeitinho brasileiro", se involucran con la cultura jurídica, porque se trata de un comportamiento cultural que, favoreciendo élites, alcanzaría magistrados, fiscales, litigantes y otros actores del campo jurídico.

\subsubsection{La percepción de la cultura jurídica y el de- recho fundamental a la identidad cultural desde los operadores jurídicos}

En este apartado -según se desarrolló en la descripción metodológica inicial- presentamos una síntesis de las entrevistas a actores jurídicos chilenos y brasileños, sintetizando una aproximación a sus concepciones de la cultura jurídica y la relación de ella con el derecho a la identidad cultural. Así, en esta parte, la propuesta de metodología busca: (i) una descripción de la cultura jurídica desde la comprensión de los operadores del respectivo campo jurídico; (ii) una descripción de los actores del campo jurídico de cómo esa cultura jurídica ha recepcionado el derecho a la identidad cultural.

\footnotetext{
118 BARROSO, Luis Roberto. Ética e jeitinho brasileiro: por que a gente é assim. Ponencia presentada en la Brazil Conference, Universidad de Harvard, 2017. Consultor Jurídico, 10 abr. 2017. p. 5. Disponivel em: https://www.conjur.com.br/2017-abr-10/leia-integrapalestra-barroso-jeitinho-brasileiro.

119 BARROSO, Luis Roberto. Ética e jeitinho brasileiro: por que a gente é assim. Ponencia presentada en la Brazil Conference, Universidad de Harvard, 2017. Consultor Jurídico, 10 abr. 2017. p. 5-7. Disponivel em: https://www.conjur.com.br/2017-abr-10/leia-integrapalestra-barroso-jeitinho-brasileiro.; HOLANDA, Sérgio Buarque de. Raízes do Brasil. Rio de Janeiro: José Olympio, 1991; p. 134-148. SILVEIRA SIQUEIRA, Gustavo. Movimentos sociais e cultura jurídica brasileira. Revista Direitos Culturais, v. 5, n.8, 2010.
}

5.3.3.1. La percepción de la cultura jurídica y el derecho fundamental a la identidad cultural desde los operadores jurídicos en el caso chileno (entrevistas):

\section{¿Qué entiende por cultura jurídica?}

Señala un abogado defensor de indígenas:

\begin{abstract}
La cultura jurídica es como nos regimos, partiendo del hecho de que hay tres poderes del Estado; Poder ejecutivo, Legislativo, y Judicial, y la Carta Magna que es la Constitución yo creo que todo en cierto modo tenemos un poquito de cultura jurídica. Después uno ya empieza a tener un concepto más técnico de cultura cuando entra a la universidad, a saber, la terminología jurídica, a usar correctamente el vocabulario jurídico también a la hora de enfrentarse a un proceso oral o a un proceso escrito, utilizar correctamente los tecnicismos o las palabras que uno pudiese emplear. ${ }^{120}$
\end{abstract}

Se enfatiza por este actor que la cultura jurídica supone un aprendizaje formal e informal de diversas valores, principios y actitudes a adoptar en el actuar profesional. En este mismo sentido, un juez indica que:

"En general la cultura jurídica son los principios que abordan el derecho, la buena fe, el principio de la libertad contractual en el derecho civil, el principio de indubio pro reo, también el principio de igualdad ante ley, el debido proceso. Para mí eso es cultura jurídica." ${ }^{121}$

Mientras que otro abogado defensor insiste más bien sobre sus aspectos prácticos, al mencionar que "los conocimientos propios que se ven el ámbito jurídico y que involucran a todas las partes y que van creando una cultura valga la redundancia respecto del qué hacer o del desenvolvimiento diario de todos los actores del sistema." 122 Asimismo, otro de los magistrados destaca cómo la cultura jurídica en Chile sigue muy anclada en el formalismo:

[...] hay una cultura jurídica en Chile dada en parte por la estructura judicial que tenemos de una suerte como de respeto cuasi religioso a ciertas maneras de hacerse las cosas a veces la falta de cuestionamiento ante ciertas decisiones solo porque se apartan de lo que algún superior a dicho en sentido diverso. (...) [Existe un] gran culto al formalismo, sin duda, un gran culto al statu quo, a lo que se encuentra supuestamente asentado y un cierto temor al cambio de enfoque que puede aplicar un cambio de razonamiento jurisprudencial. ${ }^{123}$

$\begin{array}{ll}120 & \text { Entrevistado E1. } \\ 121 & \text { Entrevistado E2. } \\ 122 & \text { Entrevistado E3. } \\ 123 & \text { Entrevistado E4. }\end{array}$ 
El mismo magistrado observa la permanencia de rasgos de este formalismo en la actualidad y a pesar de los cambios producidos tanto en el derecho chileno como en la sociedad chilena. Refiriéndose a la formula "con la venia de su señoría ilustrísima" que todo litigante tiene que enunciar a empezar su alegato ante una corte de apelaciones, el magistrado afirma "que esa expresión es el reflejo de lo que hablamos de cultura de pensamiento cuasi religioso o cuasi mágico de la posición de esta figura dentro del aparato judicial, eso a mí me llamó siempre la impresión y lo encontré siempre tan absurdo, porque vivimos en una república democrática, dejamos de lado la monarquía hace algún tiempo aparentemente pero no en todos los ámbitos y en este ámbito en particular tenemos este resabio monárquico muy metido en la manera de funcionar" 124 .

\section{¿Identifica el derecho a la identidad cultural en la cultura jurídica chilena?}

Un abogado privado que litiga en el ámbito penal expresa que para defender a imputados procesados en el contexto de las reivindicaciones indígenas mapuche, se puede relacionar la relativa estabilidad política de Chile con la existencia de esta cultura jurídica "en atención a que la forma de resolver conflictos es a través de un tercero imparcial que esta proporcionado por la institucionalidad del Estado [lo que] se debe al excesivo o fuerte legalismo que existe en el país. ${ }^{125}$

Expresa un defensor penal público:

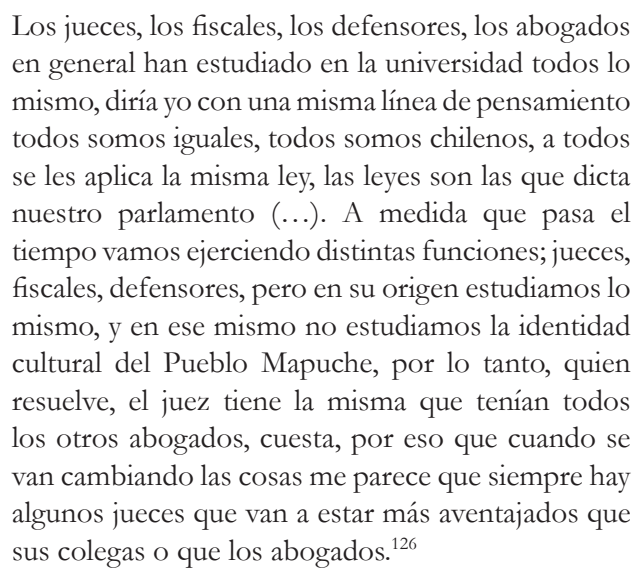

El ministro de la Corte Suprema entrevistado, sobre la diversidad cultural y el derecho fundamental a la identidad cultural expresa que:

\footnotetext{
124 Entrevistado E4.

125 Entrevistado E5.

126 Entrevistado E6.
}

La diversidad existe de todas formas y en los últimos años se ha puesto más de manifiesto con la evolución misma de la sociedad y yo pienso que es un gran desafío para las generaciones particularmente las un poco más mayores porque la gente joven los estudiantes de colegios ya lo ve en el colegio, lo viven y lo tienen incorporados a su manera de ser es a los más mayores a los que nos cuesta más.

Es un gran aporte para la cultura en general, no es una sola línea sino que son varias líneas que se incorporan, se entrecruzan y permiten ampliar la visión, por ejemplo con lo que piensa la persona indígena, lo que piensa la persona migrante, lo que piensa la persona homosexual que se yo, hay toda una cantidad de variantes que uno incorpora y al incorporarlas nace un sentido más respetuoso y un sentido más democrático".

En relación al derecho a la identidad cultural y su ejercicio por personas indígenas en tribunales, el magistrado de la Corte Suprema señala que:

$[. .$.$] todas las personas en situación de vulnerabilidad$
tendrían que [tener] un trato especial sin producir
un desequilibrio, la idea siempre es que las partes
en los conflictos estén en equilibrio, suponemos
que las personas en situación de vulnerabilidad está
en desequilibrio entonces todo lo que nosotros
hagamos desde una ley hasta una buena práctica
es para que estén en equilibrio y ahí entonces
poder administrar justicia. Entonces si al migrante
nosotros le ponemos un traductor lo hemos
colocado en situación de equilibrio y le hemos
permitido al juez además entender, ese es el aporte
de todas estas medidas que apoyen y lo propio con
la persona indígena porque puede haber alguien que
le explique al juez cuales son los pensamientos, las
costumbres, las tradiciones religiosas, etc. y de esa
manera se produce el equilibrio.

\section{¿Qué interacciones visualiza entre la cultura jurídi-} ca y el derecho a la identidad cultural?

Expresa uno de los jueces entrevistados que "en todo caso, con la interrelación que hay, todas las personas conocen los tipos penales, entonces no hay mayor diferenciación entre personas de la etnia mapuche y personas chilenas." ${ }^{127}$ Por su parte, un defensor penal señala:

Existe ahora la aplicación del Convenio 169, pero creo que, como lo dije anteriormente, no han marcado mucho respecto de la aplicación del derecho. Creo yo el recurso de protección que ganó la machi francisca Linconao a un particular por la tala de un bosque nativo. Creo que eso marco mucho porque en ese tiempo aún no se había implementado el Convenio 169 en Chile, pero se 
entendió en esa resolución que se debía aplicar los derechos de los pueblos indígenas y se hizo una pseudo aplicación de ese convenio, por lo tanto creo que es un hito súper importante y creo que ahí un hito que marca un antes y un después en la aplicación de justicia de los pueblos indígenas. ${ }^{128}$

El magistrado de la Corte Suprema, sobre la recepción por parte de los tribunales de la diversidad e identidad cultural, señala:

Yo pienso que... los esfuerzos se han desplegado
en algunos casos por algunos magistrados pero no
es todavía suficiente porque esto es un proceso que
está en marcha entonces el acceso a la justicia de las
personas en situación de vulnerabilidad es algo que
de a poco se ha ido incorporando a la cultura de los
magistrados y del personal de los tribunales y este
tema de la diversidad cultural también. Entonces
paulatinamente tendremos que ir avanzando en eso.

Sobre cómo se evidenciarían esos avances indica que:

[...] la forma es muy simple es el caso que llega al tribunal que se mira con un enfoque diferente ya no es Pedro contra Juan sino que es Pedro contra Juan migrante, Pedro contra Juan indígena, Pedro contra Juana mujer migrante e indígena por decir. Entonces la visión es diferente porque hemos hecho un esfuerzo en ese sentido, los tribunales también lo han hecho, hay múltiples actividades en los tribunales y el tema de la raíz cultural diferente también tiene que llegar a ser parte de la consideración ha sido en algunos casos de alguna manera... históricos [leading case]pero todavía no están como absolutamente impregnados [internalizados].

En particular, sobre cómo el sistema de justicia chileno enfrenta las cuestiones sobre derechos del Pueblo Mapuche y, indica el juez de la Corte Suprema "que todavía el Estado de Chile no se pone muy de acuerdo de cómo entenderse con la cultura mapuche, los jueces no son mapuche, entonces tienen que hacer el esfuerzo por incorporarse, etc.". Agrega que se trata de una relación "un poco precaria salvo casos especiales en que el tribunal está preparado, lo entiende bien y actúa en consecuencia”.

Finalmente, al Magistrado de la Corte Suprema se le consultó sobre el cumplimiento de las decisiones de la Corte IDH, en particular por una condena a Chile, en que se hizo referencia al derecho fundamental a la identidad cultural" ${ }^{129}$. Expresó que "hemos reconocido

\footnotetext{
128 Entrevistado E8.

129 Corte IDH. Caso Norín Catrimán y otros (dirigentes, miembros y activista del pueblo indígena mapuche) VS. Chile. Sentencia
}

que existe una Corte Interamericana y que sus decisiones son vinculantes y no porque lo digamos nosotros, sino porque los países, Chile en este caso, lo dijo cuándo firmó y cuando adhirió al convenio [CADH]. Entonces esto es una consecuencia de haber adherido al convenio y de habernos incorporado a ese sistema [SIDH]. Entonces, las discusiones que se produjeron [porque] todavía no hemos evolucionado en conjunto respecto de este asunto y que vamos a mantener discrepancia y que nos va costar mucho...".

\section{Análisis entrevistas campo jurídico chileno.}

Estas distintas perspectivas permiten poner en relación el ámbito jurídico con otras esferas de la sociedad, como es la social y la política. La cultura jurídica sigue apareciendo como un ente regulador de estas distintas dimensiones. Al mismo tiempo, la cultura jurídica aparece como un punto de tensión y de crítica, vector de subjetivación de los actores jurídicos en su quehacer cotidiano.

Parte de los debates en los tribunales, se relacionan con los principios y reglas, supuestamente veladas por la cultura jurídica, como es imparcialidad del juez, el respeto de las garantías, generando un espacio de discursividad y de formación de un régimen de verdad similar a la meta-cultura, según es definida por Briones ${ }^{130}$. Así, la emergencia del derecho a la identidad cultural en Chile ha constituido un punto de tensión entre los actores jurídicos, y de forma más amplia en la sociedad regional y nacional, al imponer un cambio de paradigma en sus formaciones tal como le expresó un defensor público entrevistado o, a lo menos, un grado de avance aún insuficiente, en perspectiva de un Ministro de la Corte Suprema. Asimismo. De la voz de los distintos actores jurídicos entrevistados, el derecho a la identidad cultural se ejerce, principalmente, a través del derecho a hablar su propio idioma por intermedio de facilitadores interculturales, e invocar la ley indígena y el Convenio 169 de la OIT.

Como señaló uno de los jueces entrevistados, finalmente, la comprensión de los actores jurídicos sobre el derecho a la identidad cultural se refiere a "diferencias en cuanto a la apreciación cultural", pero que, en definitiva, no considera que exista "mayor diferenciación entre personas de la etnia mapuche y personas

de 29 de mayo de 2014 (fondo, reparaciones y costas).

130 BRIONES, Claudia. (Meta) cultura del estado-nación y estado de la (meta) cultura. Brasília: 1998, 244. Série Antropologia. p. 6-7. 
chilenas." ${ }^{31}$. Tal posición compartida por otros actores jurídicos, en particular magistrados y fiscales, se sustenta sobre lo que Wladimir Martínez ha llamado "El trato impersonal y la "fetichización" de los procedimientos formales" en los tribunales que "contribuyen a la conformación de una "cosmovisión jerárquica" que invisibiliza las diferencias, al omitir la presencia de los mapuche en los espacios judiciales, bajo un marco ideológico que sostiene el carácter universal del sujeto de derecho moderno occidental." ${ }^{132}$ Mientras que abogados defensores, en particular aquellos que defienden casos involucrando a personas mapuche, visualizan a la misma vez las dificultades estructurales del derecho chileno de recurrir a normativas especiales como el convenio 169, a la vez que perciben algunos avances que dan cuenta del potencial de sus usos y aplicaciones.

Mientras que abogados defensores, en particular aquellos que defienden casos involucrando a personas mapuche, visualizan a la misma vez las dificultades estructurales del derecho chileno de recurrir a normativas especiales como el convenio 169, a la vez que perciben algunos avances que dan cuenta del potencial de sus usos y aplicaciones.

\subsubsection{La percepción de la cultura jurídica y el de- recho fundamental a la identidad cultural desde los operadores en el caso brasileño (entrevistas):}

\section{¿Qué entiende por cultura jurídica?}

Señala un juez de competencia constitucional que:

[...] la cultura jurídica es definida de forma diversa a partir de los roles y espacios que ocupan los operadores; que puede ser definida desde un modo general del lenguaje y de forma especial en el lenguaje jurídico, a partir del lugar desde donde el observador ve $[\ldots]$ no creo que haya un concepto deontológico de cultura jurídica que se auto explique... [Por ello] no es posible tener una única percepción de todos los actores, porque dependiendo de qué actores jurídicos estemos hablando, el lugar del habla también demarca la racionalidad en la cual se coloca el actor jurídico ${ }^{133}$.

Otros actores jurídicos describen el concepto de cul-

\footnotetext{
131 Entrevistado E7.

132 Martínez, H. Producción de la diferencia en los espacios de justicia: una aproximación etnográfica al proceso de atención de usuarios mapuche en tribunales de justicia de La Araucanía: actividad formativa equivalente para optar al grado de magíster en Antropología. Temuco: Universidad Catolica de Temuco, 2019. p.72.

133 Juez tribunal superior 1.
}

tura jurídica en sus diversas dimensiones. Señalan que la cultura jurídica, genéricamente, corresponde:

[...] a la comprensión que tenemos de nuestras tradiciones jurídicas y de nuestra formación, de los objetivos de nuestra legislación, de nuestra formación de Derecho, de nuestra Constitución, etc. ${ }^{134}$

Así, se describen varios enfoques en la comprensión de la cultura jurídica. Por ejemplo: un pensamiento tradicional, académico o formal de la cultura jurídica, que se pregunta:

[...] cuál es el conjunto de manifestaciones que consideramos Derecho y que consideramos vinculantes: qué entendemos, cuáles son los límites de la interpretación (por ejemplo), cómo interpretamos, cuál es la ordenación de los precedentes en nuestro ordenamiento jurídico, hasta dónde puede llegar el juez, cuál es el límite del juez, hasta dónde puede ir el parlamento, cuál es el límite del parlamento, etc. ${ }^{135}$

Las respuestas a dichas preguntas son las que contornan la cultura jurídica formal. Sin embargo, existe otra comprensión de cultura jurídica que refiere a "cómo las cosas acontecen verdaderamente y lo que consideramos razonablemente aceptable"136. Bajo la perspectiva indicada, la Constitución "vale muy poco ya que las preferencia eventualmente ideológicas, políticas o subjetivas de los magistrados $-y$ de los tribunales sobre todo- son mucho más poderosas. Por tanto, tenemos dos culturas jurídicas si tuviéramos que definirlas" ${ }^{\text {"137. }}$.

Por su parte, un abogado asesor entrevistado expresa que los elementos que integran la cultura jurídica son:

"todos los factores que interfieren en el proceso de decisión del Supremo [STF]. Tanto es así que, ellos que tradicionalmente deberían influenciar - que es lo que aprendemos en la facultad y yo llamo de material jurídico ortodoxo - que es desde el derecho positivo hasta las técnicas más modernas o contemporáneas de interpretación, pero que son material jurídico. Yo creo que la cultura jurídica se integra por eso y por los otros factores que intervienen en el proceso de decisión: el background de los magistrados, la dinámica que existe entre ellos en la Corte, etc. Creo que todo eso es parte de la cultura jurídica"138.

\footnotetext{
Periodista especialista en cobertura judicial.

135 Asesor 1.

136 Asesor 1.

137 Asesor 1.

138 Asesor 1
} 
Contextualizando la cultura jurídica en Brasil, señalan los ministros del tribunal superior entrevistados que:

[...] cuando se pensó en el Código Civil brasileño el concepto de cultura jurídica fue agasajado por la noción de cultura jurídica europea... no se desarrolló un concepto de cultura jurídica a partir de la pluralidad social, de los pueblos y de las relaciones que había genuinamente en Brasil [Sin embargo] lo que se proyectó para la constitución del 88, fue un retrato más fidedigno de una comprensión abierta, plural y principiológica de cultura jurídica, colocándose en la Constitución esa dimensión de la realidad brasileña que no es lineal, monofásica ni excluyente" ${ }^{\prime 139}$.

"Tuvimos, por lo tanto, un discurso constitucional inclusivo y en ese discurso inclusivo, las diversas formas de ser y estar pasaron a formar parte de la narrativa constitucionalizada y, por lo tanto, del ordenamiento jurídico... Esto significa que, consecuentemente, la pluralidad supone diferentes formas de percibir jurídicamente la realidad. No me refiero tan solo a los pueblos indígenas de Brasil, que son obviamente pueblos para la Constitución y en este sentido, la versión polisémica que el concepto de cultura necesita tener, sino también a las diferentes formas de vivir" ${ }^{\prime 10}$.

"En las últimas décadas del siglo XX, hubo un fenómeno que fue una cierta transición de la Constitución para el centro del sistema jurídico [...] un derecho que era predominantemente legislado, de base privatista y con un papel limitado para jueces y tribunales, se transforma en un derecho constitucionalizado en el que la interpretación se flexibiliza, se libera de las categorías del formalismo jurídico y vive un momento de preminencia del poder judicial y, sobre todo, de las Cortes Supremas o Cortes Constitucionales ${ }^{141}$.

Desde la perspectiva de las funciones de magistrado en un tribunal constitucional, se señala que:

[...] se trata de un actor jurídico que no prescinde de una cosmovisión sobre esa narrativa constitucional; en otras palabras... no hay texto sin contexto... Entonces, un texto constitucional comprometido con los derechos fundamentales... que dibuja al reconocimiento jurídico de la pluralidad de los modos de ser y estar- es un texto que cumple también un papel de emancipación, proactivo, donde las posibilidades evidentemente son abiertas, sobre todo, en un estado democrático de Derecho. ${ }^{142}$
En relación a la práctica de los abogados -agrega uno de los magistrados constitucionales- Brasil ha verificado "una cierta constitucionalización del debate jurídico y una cierta judicialización de la vida". Por esa razón, que "la cultura jurídica brasileña también se constitucionalizó ampliamente... el derecho judicializado (el derecho ante los tribunales) vivió un proceso de impacto de la constitucionalización" ${ }^{143}$.

Los Ministros de competencia constitucional entrevistados, finalmente, coinciden en el rol central que con la Constitución de 1988 adquirió el Ministerio Público que, "dotado de una autonomía e independencia extraordinarias", se constituyó, no tan solo un perseguidor criminal, sino "como un defensor de las minorías y las pluralidades"144, en particular de grupos como los indígenas y del medio ambiente, de tal forma que "la justicia brasileña se estructura sobre este trípode: jueces, abogados y Ministerio Público" ${ }^{145}$.

Algunas características (negativas) que se identifican dentro de la cultura jurídica brasileña son:

"el patrimonialismo - que es una mala separación entre el espacio público y privado;... el exceso de la presencia del estado en todos los dominios de la vida; y una cultura de desigualdad -nosotros heredamos de los colonizadores una idea de que hay superiores e inferiores y hay algunos que están sujetos a la ley y otros que están fuera y sobre la ley -, de forma que hay trazos de la formación cultural latinoamericana que necesitamos enfrentar y superar" ${ }^{\prime 14}$.

\section{¿Identifica el derecho a la identidad cultural en la cultura jurídica brasileña?}

Señalan los magistrados de competencia constitucional que:

“... la identidad cultural, quiero decir, un país como Brasil es multicultural.

Nosotros tenemos una identidad europea (sobre todo portuguesa), una identidad africana (que hoy representa cerca de la mitad de la población) y tenemos influencia indígena (que eran las poblaciones nativas aquí de América Latina.

Una característica de la identidad cultural brasileña
139 Juez tribunal superior 1 .

140 Juez tribunal superior 1.

141 Juez tribunal superior 2.

142 Juez tribunal superior 1
143 Juez tribunal superior 2.b

144 Juez tribunal superior 1.

145 Juez tribunal superior 2.

146 Juez tribunal superior 2. 
es un binomio mestizaje-multiculturalismo, que es un trazo muy fuerte en la vida brasileña y repercute en el biotipo de las personas, en la música, en un cierto joie-de-vivre (una cierta alegría de vivir) que es una característica muy fácil de encontrar en Brasil. Por lo tanto, la mezcla de razas en Brasil, produjo un paquete multirracial y multicultural que creo que puede ser una buena referencia para el mundo. Ahora, hasta hoy nosotros nos enfrentamos a secuelas de la cuestión social generadas por la esclavitud y por la liberación de los esclavos al final del siglo XIX... produjo una discriminación, una segregación histórica de las poblaciones negras en Brasil que viene siendo enfrentado únicamente en los últimos años, en las únicas décadas.

En cuanto a las poblaciones indígenas, fueron diezmadas en Brasil como en el resto de América Latina. Existe aún, residualmente, tal vez 500000 indios en una población de más de 200 millones de habitantes. En los últimos años, se desarrolló una percepción (por lo menos en los círculos más progresistas) de que hay una deuda histórica con las poblaciones indígenas y, por lo tanto, incluso en la élite dominante tenemos personas que se preocupan con la demarcación adecuada de tierras indígenas y respeta sus derechos, pero este es un proceso que tiene idas y vueltas" 147.

"En el Brasil contemporáneo, la cultura jurídica acaba siendo resignificada, por lo tanto, en una dimensión de sociedad plural, en la que hay diálogos con diferentes modos de ser y de estar. De ahí la importancia que tiene en Brasil, así como en los otros pueblos de América, la cuestión indígena, la cuestión quilombola y de un conjunto de nichos de ser y de estar que son distintos de aquella importación europea que, de algún modo, propició la colonización tanto territorial como cultural ${ }^{148 "}$.

\section{¿Qué interacciones visualiza entre la cultura jurídi- ca y el derecho a la identidad cultural?}

Describe uno de los ministros entrevistados que:

[...] en estos últimos 30 años, los actores jurídicos en Brasil - de forma general - y el discurso jurídico respectivo, abrió un espacio muy grande para la comprensión de la diversidad cultural que forma la pluralidad de pueblos dentro de la nación y, por tanto, de una nación inclusiva de aquello que se puede denominar como pueblos del bosque, por decirlo de alguna forma. Una dimensión que trae, para la actuación y el discurso jurídicos, el reconocimiento de que cada uno puede ser lo que es sin que el otro también deje de ser aquello que es. Ese respeto de la diversidad y el respeto también, que nosotros aún estamos de alguna forma construyendo, con el concepto de autodeterminación, para reconocer que los pueblos indígenas no tienen únicamente una identidad distinta, un modo de ser y de estar distinto, que precisan ser integralmente respetados incluso cuando confrontan el modo de ser y de estar de la sociedad, del entorno; y, por lo tanto, de todos los demás componentes del concepto de pueblo. Especialmente desde que, como todos nosotros sabemos, para los pueblos indígenas existe otra cosmovisión acerca sí mismos, acerca de su tierra, acerca de la relación que tienen entre sí, con las cosas que forman su "cultura".

De esa manera, nosotros salimos de esos últimos 30 años de una invisibilidad a una visibilidad identitaria que está reconocida en la Constitución. Esa consecuencia que se dio, evidentemente, no fue una mera concesión sino una conquista que se da en la Constitución brasileña, especialmente como reconocimiento de las espacialidades territoriales de los indígenas de modo general. El desafío que existe hoy es, en realidad, mantener esta conquista identitaria y si fuera posible, dar algunos pasos más en el reconocimiento de las respuestas diversas que los pueblos tienen dentro de un mismo territorio, sobre problemas y cuestiones que integran su forma de ser y estar.

[la Constitución de 1988] no es un punto de llegada, es tan solo una estación de ese camino que, además de colocar como desafío contener un retroceso, se precisa mirar al frente para que haya - además de la identidad - el reconocimiento de autodeterminación, que es un paso no dado aún en Brasil, requiriendo el discurso de los agentes o actores jurídicos" ${ }^{\prime 14}$.

Por último, en relación con la formación de los abogados un abogado señala que:

[...] muy poca gente conoce la cuestión indígena. Yo, por ejemplo, me gradué en Derecho, hice maestría en Derecho y doctorado en Derecho. Yo no leí - ni en la graduación, ni en la maestría, ni en el doctorado - ni un solo texto sobre el Derecho aplicado a los indígenas... Entonces ni sabía que existía la categoría quilombola, porque el indígena ... nosotros conmemoramos el Día del Indio: en la escuela nos poníamos un cocar [sombrero usado por los indígenas], nos pintábamos la cara y cantábamos canciones... Pero ese es todo el contacto que los brasileños tiene con el indio. El indio es aquella persona de cocar, que pinta su rostro y que una vez al año conmemoramos el Día del Indio (hacemos un baile para que nuestros padres lo vean en la escuela, hacemos algún regalito para los padres, etc.). ${ }^{150}$
147 Juez tribunal superior 2.

148 Juez tribunal superior 1.
149 Juez tribunal superior 1.

150 Asesor 1. 


\section{Análisis entrevistas campo jurídico brasileño}

En general los actores jurídicos coinciden en tres rasgos fundamentales de la cultura jurídica brasileña en relación al derecho fundamental a la identidad cultural. Por una parte, Brasil evidencia una transición desde mediados del siglo XX, marcada por el cambio constitucional de 1988, que conlleva un cambio progresivo, de una cultura jurídica formalista, hacia una cultura jurídica más hermenéutica centrada en la constitucionalización del Derecho, con preponderancia de los valores, principios constitucionales y de los derechos fundamentales.

En segundo lugar, conjuntamente con el proceso descrito, a partir de la Constitución de 1988, también se evidencia una progresiva apertura, en el ámbito normativo, al reconocimiento de la multiculturalidad constitutiva de la sociedad brasileña. Este nuevo marco constitucional reconoce ampliamente la diversidad del pueblo brasileño, a los pueblos indígenas, su derecho a su identidad cultural, derechos territoriales, etc. Además, dicho reconocimiento de la diversidad, incluye a otros grupos vulnerables como los quilombolas, con su propio estatuto constitucional de derechos.

$\mathrm{Y}$, en tercer término, también se constata, que las aperturas indicadas no son lineales, sino que están marcadas por los propios contextos y factores extrajurídicos que influyen en las decisiones, los elementos no normativos de la cultura jurídica, como la formación de los abogados y las prácticas subsistentes, que dificultan esos procesos. Con todo, los magistrados entrevistados admiten que los derechos reconocidos en la Constitución de 1988 (i) son derechos "conquistados", no regalías, (ii) relevan las dificultades, como pasos necesarios de ir superando progresivamente, (iii) bajo el imperativo de no retroceder en lo avanzado, como logro de un Estado den Derecho Democrático.

\section{Conclusiones}

La comprensión del alcance del derecho extranjero no debe basarse solo sobre su texto, debe tener en cuenta la cultura jurídica, porque ella es profundamente determinante de cómo opera el sistema normativo y, en especial, de cómo deciden los tribunales. Por ejemplo, un mismo instituto, como el derecho a la identidad cultural, puede implicar prácticas muy distintas en diferentes universos culturales, ergo, decisiones judiciales también diversas. No obstante, si se avanza en la convergencia conceptual y normativa, las cortes domésticas pueden acercar sus comprensiones. Por ello, el estudio realizado contempló: (i) una dimensión normativa positiva (textual), (ii) otra normativa hermenéutica (jurisprudencial) y (iii) la sociocultural (cultura jurídica, propiamente tal). En este sentido, las controversias y litigios jurídicos en que se disputan cuestiones radicadas en el derecho a la identidad cultural de pueblos indígenas y otros grupos vulnerables, tienen un impacto en la transformación del derecho y de la justicia y se producen en gran parte en la "arena" de la cultura jurídica.

En la dimensión normativa de sus respectivas culturas jurídicas, la Constitución Federal de Brasil de 1988 y la Constitución Política de Chile de 1980, se diferencian porque la primera contempla un marco amplio de derechos de los pueblos indígenas y quilombolas. Mientras, la segunda, omite este reconocimiento. No obstante lo anterior, los precedentes constitucionales han sido la vía para conformar un marco constitucional, normativo hermenéutico, de reconocimiento del derecho fundamental a la identidad cultural. En el caso brasileño para ampliar y o delimitar este derecho. En el caso chileno, como mecanismo de reconocimiento hermenéutico constitucional, en sí. Este desarrollo de precedentes no ha sido pacífico, por el contrario, se evidencian interpretaciones en tensión y disputas, más o menos "proteccionistas", sobre el derecho a la identidad cultural de indígenas y grupos culturalmente identitarios y vulnerables.

En relación a los precedentes estudiados, en el campo jurídico brasileño, se pueden identificar sentencias sobre el reconocimiento de la "tradicionalidad" del uso y la demarcación de las tierras indígenas; del reconocimiento de las tierras de los quilombolas; y también, en el ámbito de la libertad religiosa, con el reconocimiento de las religiones de matriz africana y sus prácticas sacrificiales de animales. Con todo, en Brasil sigue abierta - "en disputa" la cuestión de los pueblos indígenas y la protección de los recursos naturales en sus territorios. Por su parte, en el campo jurídico chileno, hermenéuticamente, la Corte Suprema viene aplicando en sus fallos sostenidamente el Convenio Nº169 de la OIT, conforme la apertura constitucional (artículo 5 inciso $2^{\circ}$ ) al Derecho Internacional de los derechos humanos. Esta jurisprudencia superior ha llegado a reconocer derechos de carácter cultural a los indígenas y con ello se ha abierto un camino normativo de admisión del derecho fundamental a la identidad cultural, permeando la 
propia cultura jurídica chilena hegemónica. Así, el reconocimiento del derecho a la identidad cultural y de su irradiación a otros derechos es una cuestión disputada, sujeta a avances y retrocesos.

En Brasil, como decíamos, si bien el texto positivo constitucional de 1988 contempla el reconocimiento de los derechos culturales de grupos minoritarios, la cultura jurídica constitucional es más conservadora respecto a la permeabilidad del Derecho Internacional de los derechos humanos. En particular, desde la Constitución de 1988 en adelante, se reconoce expresamente a los pueblos indígenas y otras minorías culturales como las afrodescendientes, asegurándoles un estatuto de derechos. Pero, aunque formalmente se han ratificado los instrumentos internacionales de derechos humanos más relevantes, su tradición hermenéutica ha dialogado de forma débil con el Derecho Internacional de los Derechos Humanos. Ello, en particular, ha significado un lento proceso de reconocimiento del derecho fundamental a la identidad cultural de pueblos indígenas y afrodecendientes. Entonces, si bien en Brasil existen bases positivas claras para el reconocimiento del derecho fundamental a la identidad cultural, tanto en los fundamentos constitucionales y como de Derecho Internacional, la eficacia del mandato constitucional es resistido desde la cultura jurídica dominante.

En relación con las culturas jurídicas y los actores jurídicos, en ambos casos, en el ámbito de derechos territoriales y otras categorías, aunque formalmente los instrumentos internacionales han pasado a formar parte del ordenamiento jurídico chileno y brasileño, la cultura jurídica de jueces y otros actores no los internalizó de forma inmediata ni contundente, sino que solo progresivamente. Con todo, hoy se constata una fisura sobre las comprensiones marcadas por el positivismo jurídico, bajo fuerte influencia de las sentencias de la Corte Interamericana de Derechos Humanos. En este sentido, se han podido constatar diversas prácticas, discursos y sentencias a nivel local, de apertura a la diversidad sociocultural que, por sobre las visiones de carácter positivista y o discriminatorias aún persistentes, tienden a hacer pensar en la emergencia de cambios significativos en materia de reconocimiento de particularidades socioculturales en el ámbito jurídico y con ello el reconocimiento normativo de la identidad cultural, aunque aún en una fase inicial, con tensiones y disputas.
En ambos campos jurídicos, el marco de reconocimiento constitucional argumentado se ha fundamentado, principalmente, en el carácter de "grupos vulnerables" de indígenas y otros grupos. Consecuentemente, en el deber de protección que tiene el Estado, desde el punto de vista del principio de igualdad, de generar acciones afirmativas de tutela. Ello, si bien es un avance en ambos casos, constituye una comprensión limitada del derecho fundamental a la identidad cultural, en especial respecto de los pueblos indígenas y otros grupos titulares de autodeterminación. En estos casos, no es solo cuestión de vulnerabilidad, ni de identidades diferentes, sino quede titularidad de derechos colectivos frente al Estado, que pueden confrontar los modos de ser hegemónicos y colisionar con otros derechos e intereses sociales. En este campo, si bien se declaran comprensiones más o menos abiertas a la diversidad cultural, las culturas jurídicas también reflejan tensiones, avances y retrocesos.

El estudio comparado de los impactos de la cultura jurídica en los procesos de trasformación del Derecho exige el desarrollo de metodologías complejas, interdisciplinarias, adecuadas, creativas y dúctiles a dichos contextos identitarios, que superen las técnicas clásicas del Derecho Comparado positivista, introduciendo enfoques aportados desde las otras Ciencias Sociales.

De esta forma, desde el punto de vista metodológico, pudimos identificar distintos rasgos y efectos compartidos que dan la oportunidad para desarrollar investigaciones comparativas en torno a las transformaciones en el campo jurídico. En particular, las abordamos desde los impactos que genera el reconocimiento del derecho a la identidad cultural, emergente y en acción, desde una perspectiva comparativa e interdisciplinar, considerando distintas escalas de observación y análisis. Primero, se revisó desde los entramados de la cultura jurídica de los operadores de los sistemas de justicia, cuál es la visión sobre el trato y los derechos de los indígenas y miembros de otros grupos vulnerables. Segundo, desde la observación descrita, avanzamos en una propuesta metodológica, para el estudio de la cultura jurídica, pertinente a contextos regionales latinoamericanos comparados, en relación con el derecho a la identidad cultural de pueblos indígenas u otros grupos vulnerables. 


\section{Referências Bibliográficas}

AGUILAR, Gonzalo. Emergencia de un derecho constitucional común en materia de pueblos indígenas. En: VON BOGDANDY, Armin; FERRER MACGREGOR, Eduardo, MORALES-ANZIONATTI, Mariela (Eds.). La justicia constitucional y su internacionalización. ¿Hacia un Ius Constitucionale Commune en América Latina? Tomo II. México: UNAM, MPI, IIADC, 2010. p. 3-84.

AMORIM, Fabrício, BURGER, Leila, RODRIGUES, Patrícia, ALCANTARA E SILVA, Victor. Silenced genocides: genocídios silenciados. São Paulo: IWGIA/ GAPK, 2019.

AYLWIN, José; MEZA-LOPEHANDÍA, Matías; YAÑEZ, Nancy. Los pueblos indígenas y el derecho. Santiago: LOM, Observatorio Ciudadano, 2013.

BARROSO, Luis Roberto. Curso de direito constitucional contempoâneo: os conceitos fundamentais e a contrução de novo modelo. Sao Paulo: Saraiva jur, 2019.

BARROSO, Luis Roberto. Ética e jeitinho brasileiro: por que a gente é assim. Ponencia presentada en la Brazil Conference, Universidad de Harvard, 2017. Consultor Jurídico, 10 abr. 2017. p. 5. Disponible en: https:// www.conjur.com.br/2017-abr-10/leia-integra-palestrabarroso-jeitinho-brasileiro.

BERHO, Marcelo; CASTRO, Paulo; LE BONNIEC, Fabien. La pericia antropológica en La Araucanía de Chile: entre teorías y prácticas, 2003-2014. Antropologías Del Sur, v. 16, n. 3, p. 107-126, 2018.

BINDER, Alberto. Los oficios del jurista: la fragmentación de la profesión jurídica y la uniformidad de la carrera judicial. Academia: revista sobre enseñanza del derecho de Buenos Aires, n. 5, p. 85-116, 2005.

BOGDANDY, Armin von; MORALES ANTONIAZZI, Mariela; FERRER MAC-GREGOR, Eduardo (coord). Ius Constitutionale Commune en América Latina: textos básicos para su comprensión. Querétaro: Instituto de Estudios Constitucionales del Estado de Querétaro; Max Planck Institute for Comparative Public Law and International Law, 2017.

BOGDANDY, Armin von; ANTONIAZZI, Mariela Morales; PIOVESAN, Flávia (coord). Ius constitutionale commune na América Latina: diálogos jurisdicionais e controle de convencionalidade. Curitiba: Juruá,
2016. v. 3

BOLADOS GARCÍA, Paola; BOCCARA, Guillaume. Du néolibéralisme multiculturel aux mobilisations postmulticulturelles. Actuel Marx, v. 56, n. 2, p. 74, 2014.

BOURDIEU, Pierre. Les juristes, gardiens de l'hypocrisie collective. En: CHAZEL, François; COMMAILLE, Jacques (eds.). Normes juridiques et régulation sociale. Paris: LGDJ, collection Droit et société, 1991. p. 95-99.

BRASIL. Supremo Tribunal Federal. Ação popular, Petição no 3.388. Relator: Ministro Ayres Britto. Brasília, 19 de março de 2009.

BRASIL, Supremo Tribunal Federal. ADI 3239, 2018.

BRASIL, Supremo Tribunal Federal. RE 494.601, 2019.

BRASIL, Supremo Tribunal Federal, ADI 4.983. Relator: Ministro Marco Aurélio. Brasília 06 de outubro de 2016.

BRIONES, Claudia. (Meta) cultura del estado-nación y estado de la (meta) cultura. Brasília: [S. n.], 1998. Série Antropologia, 244.

BUSTOS, Rafael. Pluralismo constitucional y diálogo jurisprudencial. México: Porrúa, 2012.

BUSTOS, Rafael. La Constitución red: un estudio sobre supraestatalidad y constitución. Bilbao: Instituto Vasco de Administración Pública, 2005.

CARMONA, Cristóbal. La aplicación del derecho a consulta del convenio 169 de la OIT en Chile: hacia una definición de su contenido sustantivo: afectación e instituciones representativas. En: MIRANDA, Ricardo y CARMONA, Cristóbal. Tesis (maestría) sobre pueblos indígenas. v.3. Colección Tesis de Maestría U. Nacional San Martín de Buenos Aires. Buenos Aires: U. Nacional de San Martín, CIEP, 2013.

CENTRO DE ESTUDIOS DE JUSTICIA DE LAS AMÉRICAS. Reforma procesal penal y pueblos indígenas. 2015. Disponible en: http://biblioteca.cejamericas.org/bitstream/handle/2015/5129/ RPPYPUEBLOSINDIGENAS_IMARENSI. pdf ? sequence $=1$ \&isAllowed $=\mathrm{y}$.

COMMAILLE, JACQUES (eds). Normes juridiques et régulation sociale. Paris : LGDJ, collection Droit et société, 1991, p. 95-99. 1991.

CENTRO DE ESTUDIOS DE JUSTICIA DE LAS AMÉRICAS. Reforma procesal penal y pue- 
blos indígenas. 2015. Disponible en: <http://biblioteca.cejamericas.org/bitstream/handle/2015/5129/ RPPYPUEBLOSINDIGENAS_IMARENSI. pdf? sequence $=1$ \&isAllowed $=\mathrm{y}>$.

CHILE. Corte de Apelaciones de Temuco. Rol 17732008, 16 septiembre 2009. Confirmada, Corte Suprema, Rol 7287-2009, 30 noviembre 2009, Cons. $4^{\circ}$ y $13^{\circ}$.

CHILE. Corte Apelaciones Valdivia. Rol 501-2011; (revoca) Corte suprema, Rol 3.863-2012.

CHILE. Corte Apelaciones Valdivia. Rol 651-2012, 7 diciembre 2012. Corte Suprema, Rol 481-2013, 23 septiembre 2013.

CHILE. Corte Suprema. Rol 3010-2013, 26 septiembre 2013.

CHILE. Corte Suprema. Rol 7287-2009, 30 noviembre 2009.

CHILE. Corte Suprema. Rol 2840-2008, 25 noviembre 2009.

CHILE. Corte Suprema. Rol 10.090-2011, 22 marzo 2012.

CHILE. Corte Suprema. Rol 2840-2008, 25 noviembre 2009.

CHILE. Corte Suprema. Rol 10.090-2011, 22 marzo 2012.

CLOUD, Leslie; LE BONNIEC, Fabien. Dynamiques actuelles de criminalisation et de judiciarisation des droits autochtones au Chili. En: BELLIER, Irène; HAYS, Jennifer (eds.). Echelles de gouvernance et peuples autochtones: de nouveaux droits ou la répétition des erreurs du passé ? Paris: L'Harmattan, 2019. p. 235254.

CLOUD, L.; LE BONNIEC, F. The competing logics of the state and indigeneity: the dynamics of Mapuche territoriality in the context of indigenous peoples' right to self-determination. Quaderns de l'Institut Catala d'Antropologia, v. 17, n. 1, 2012.

COLLIOT-THÉLÈNE, Catherine. La sociologie de Max Weber Paris. Paris: La Découverte, 2006.

CORTE INTERAMERICANA DE DERECHOS HUMANOS. Caso Aloeboetoe y otros Vs. Surinam, 10 septiembre de 1993 (Reparaciones y Costas).

CORTE INTERAMERICANA DE DERECHOS HUMANOS. Caso Comunidad Garífuna de Punta Pie- dra y sus miembros Vs. Honduras, 8 octubre de 2015 (Excepciones Preliminares, Fondo, Reparaciones y Costas).

CORTE INTERAMERICANA DE DERECHOS HUMANOS. Caso de la Comunidad Indígena Sawhoyamaxa Vs. Paraguay, Sentencia de 29 de marzo de 2006.

CORTE INTERAMERICANA DE DERECHOS HUMANOS. Caso de la Comunidad Moiwana Vs. Suriname, 15 junio de 2005 (Excepciones Preliminares, Fondo, reparaciones y Costas).

CORTE INTERAMERICANA DE DERECHOS HUMANOS. Caso Norín Catrimán y otros (dirigentes, miembros y activista del pueblo indígena mapuche) VS. Chile. Sentencia de 29 de mayo de 2014 (fondo, reparaciones y costas).

CORTE INTERAMERICANA DE DERECHOS HUMANOS. Caso del Pueblo Indígena Kichwa de Sarayaku vs. Ecuador, 27 junio 2012 (Reparaciones y costas).

CORTE INTERAMERICANA DE DERECHOS HUMANOS. Caso Pueblo Indígena Xucuru vs. Brasil, j. 5 de febrero de 2018.

CORTE INTERAMERICANA DE DERECHOS HUMANOS. Caso del Pueblo Saramaka vs. Surinam, 28 noviembre de 2007 (Excepciones Preliminares, Fondo, Reparaciones y Costas).

CORTE INTERAMERICANA DE DERECHOS HUMANOS. Sentencias parcial o totalmente: Herzog y otros vs. Brasil, j. 15 de marzo de 2018;

CORTE INTERAMERICANA DE DIREITOS HUMANOS. Supervisão de Cumprimento de Sentença do Caso Escher e Outros vs. Brasil, 20 de febrero de 2012.

CORTE INTERAMERICANA DE DERECHOS HUMANOS. Supervisión de Cumplimiento de Sentencia de Favela Nova Brasília vs. Brasil, 30 de mayo de 2018.

CORTE INTERAMERICANA DE DERECHOS HUMANOS. Supervisión de Cumplimiento de Sentencia de Garibaldi vs. Brasil, 22 de febrero de 2012.

CORTE INTERAMERICANA DE DERECHOS HUMANOS. Supervisión de Cumplimiento de Sentencia de Ximenes Lopes vs. Brasil, j. 17 de mayo de 2010.

CORTE INTERAMERICANA DE DERECHOS HUMANOS. Caso Trabajadores de la Fazenda Brasil 
Verde vs. Brasil, j. 20 de octubre de 2016.

COUSO, Javier. Mapuches y Derecho Penal. In: OLEA RODRÍGUEZ, Helena (ed). Derecho y Pueblo Mapuche: aportes para la discusión. Santiago: Centro de Derechos Humanos UDP, 2013. p. 155-214.

COUSO, Javier; HILBINK, Lisa. From Quietism to Incipient Activism: The Institutional and Ideological Roots of Rights Adjudication in Chile. In: HELMKE, GRETCHEN; RÍOS-FIGUEROA, JULIO (eds.). Courts in Latin America. Cambridge: Cambridge University Press, 2011. p. 99-127.

DE LA SIERRA, Susana. Una metodología para el Derecho Comparado europeo: derecho Público Comparado y Derecho Administrativo Europeo. Madrid: Thomson, Civitas, Arazandi, 2004, p. 74-77.

DEWEY, John. La formation des valeurs. Paris: La Découverte, 2011.

DUPRET, Baudouin. Droit et sciences sociales. Pour une respécification praxéologique. Droit et société, v. 2, n. 75, p. 315-335, 2010.

EPP, Charles R. La revolución de los derechos. Abogados, activistas y cortes supremas en perspectivas comparadas. Buenos Aires: Siglo XXI, 2013.

FAUNDES, Juan Jorge. El derecho fundamental a la identidad cultural de los pueblos indígenas, configuración conforme el derecho internacional y perspectivas de su recepción en Chile. Ius et Praxis, n. 1, 2020.

FAUNDES, Juan Jorge. Consulta indígena y centrales de generación hidroeléctrica de menos de 3MW: desregulación riesgosa, a la luz del derecho fundamental a la identidad cultural de los pueblos indígenas. En: Libro III Congreso Internacional de Regulación y Consumo. Santiago: RIL, Universidad Autónoma de Chile, 2020. p. 369-373.

FAUNDES, Juan Jorge. Derecho fundamental a la identidad cultural de los pueblos indígenas: un nuevo paradigma en la defensa penal indígena en Chile frente al Estado de Derecho hegemónico. En: Revista Izquierdas, n. 45, p. 51-78, feb. 2019

FAUNDES, Juan Jorge. El derecho fundamental a la identidad cultural de los pueblos indígenas: un derechomatriz y filtro hermenéutico para las constituciones de América Latina: la justificación. Revista Brasileira de Políticas Públicas, v. 9, n. 2, 18 ago. 2019.
FAUNDES, Juan Jorge. Derechos humanos y el reconocimiento de la identidad cultural de los pueblos indígenas en América Latina, en la perspectiva crítica del descentramiento intercultural. En: OLVERA, Jorge; OLVERA, Julio y GUERRERO, Ana Luisa (coords.): Los pueblos originarios en los debates actuales de los derechos humanos. México: UNAM, CIAC, 2017. p. $39-60$.

FAUNDES, Juan Jorge. Convenio n¹69 de la OIT en la Jurisprudencia de la Excelentísima Corte Suprema en Chile. Tendencias y debates en materia de propiedad y derecho al Territorio. En: Colecciones Jurídicas de la Corte Suprema, 2015. Disponible en: http://decs.pjud. $\mathrm{cl} /$ index.php/informes/informes-academicos/62-informes-academicos-indigena/379-tendencias-y-debates-en-materia-de-propiedad-y-derecho-al-territorio.

FIGUEIREDO, Marcelo, Constitucionalismo LatinoAmericano e Cultura Constitucional. En: VON BOGDANDY, Armin, PIOVESAN, Flávia, MORALES ANTONIAZZI, Mariela (coords.). Constitucionalismo transformador, inclusacao e direitos coaciais: desafíos do IUS Constitucionale Commune Latino-Americano à la luz do Direito Econômico Internacional. Salvadora: JusPODIVM, 2019. p. 725-752, p. 728-732.

FRIEDMAN, Lawrence. The Legal System. A social science perspective. New York: Russell Sage Foundation, 1975.

FUENZALIDA, Edmundo. Cultura jurídica externa e interna en el Chile finisecular: ¿Convergencia o divergencia? En: Anuario de filosofía jurídica y social. Sociedad chilena de filosofía jurídica y social, n. 20, 2000. p 473-483

GARCÍA ROCA, Javier; FERNÁNDEZ SÁNCHEZ, Pablo; SANTOLAYA, Pablo; CANOSA, Raúl. El diálogo entre los sistemas europeo y americano de Derechos Humanos. 2. ed. Lima: ECB editores, 2015.

HENRÍQUEZ, Miriam; MORALES, Mariela. El control de convencionalidad: un balance comparado a 10 Años de Almonacid Arellano vs. Chile. Santiago: DER Ediciones. 2017.

HOLANDA, Sérgio Buarque de. Raízes do Brasil. Rio de Janeiro: José Olympio, 1991.

LATOUR, Bruno. La fabrique du droit : une ethnographie du Conseil d’État. Paris: La Découverte, 2002.

LE BONNIEC, Fabien. Juridicité autochtone et 
différence culturelle. Ethnologie française, v. 169, n. 1, p. 141, 2018.

LE BONNIEC, Fabien. Interrogantes en torno a la emergencia del peritaje antropológico en las cortes de justicia del sur de Chile. En: CARRASCO, MORITA; LUXARDO, NATALIA (eds.). El orden cuestionado: lecturas de antropología jurídica. Buenos Aires: UNSAM Edita, 2018. p. 117-130.

LE BONNIEC, Fabien; NAHUELCHEO QUEUPUCURA, Pamela. La mediación lingüístico-cultural en los tribunales en materia penal de la Araucanía. Revista de Llengua i Dret, n. 67, p. 279-293, 1 jun. 2017.

LÓPEZ MEDINA, Rocío del Carmen, Cultura jurídica, Eunomía. Revista en Cultura de la Legalidad, n. 7, p. 229-235, sep. 2014/feb. 2015.

LUHMANN, Niklas. El derecho de la sociedad. México: Universidad Iberoamericana, 2002.

MARTÍNEZ, H. Producción de la diferencia en los espacios de justicia: una aproximación etnográfica al proceso de atención de usuarios mapuche en tribunales de justicia de La Araucanía: actividad formativa equivalente para optar al grado de magíster en Antropología. Temuco: Universidad Catolica de Temuco, 2019. p.72.

MARINONI, Luiz Guilherme; MAZZUOLI, Valério de Oliveira. Apresentação. En: MARINONI, Luiz Guilherme; MAZZUOLI, Valério de Oliveira (org.). Controle de convencionalidade: um panorama latinoamericano. Brasília: Gazeta Jurídica, 2013. pp. XIII-XV.

MELLO, PERRONE, Patrícia. Constitucionalismo, transformação e resiliência democrática no Brasil: o Ius Constitucionale Commune na América Latina tem uma contribuição a oferecer? Revista Brasileira de Políticas Públicas, Brasília, v. 9, n. 2 p.253-285, 2019.

MELLO, PERRONE, Patrícia. Nos bastidores do Supremo Tribunal Federal. Rio de Janeiro: Forense, 2015.

MELLO, PERRONE, Patrícia, LACERDA ACCIOLY, Clara. El derecho fundamental a la identidad cultural y el constitucionalismo en red en la jurisprudencia del supremo tribunal federal de Brasil. En: FAUNDES Juan Jorge; RAMÍREZ Silvina (Edts.). Derecho fundamental a la identidad cultural, abordajes plurales desde América Latina. Santiago: Universidad Autónoma de Chile, 2019 (en prensa).

MELLO, PERRONE, Patrícia; FAUNDES, Juan Jorge. Constitucionalismo em rede: o direito à identidade cultural dos povos indígenas como filtro hermenêutico para tutela da tradicionalidade da ocupação da terra. In: CONGRESSO BRASILEIRO DE DIREITO SOCIOAMBIENTAL, 8., 2019, Paraná. Anais [...]. Paraná: PUC Paraná, 2019 (no prelo).

MINISTERIO DE PLANIFICACION NACIONAL Y POLITICA ECONOMICA. Instituto Nacional de Estadísticas. Estadísticas sociales de los pueblos indígenas en Chile. Censo 2002. Disponible en: https://books.google.com.br/books?id=M1bjAAAAMAAJ\&q= Estad $\% \mathrm{C} 3 \%$ ADsticas + sociales $+\mathrm{de}+\mathrm{los}+$ pueblos + ind $\% \mathrm{C} 3 \%$ ADgenas + en + Chile,+ Censo $+2002 \& \mathrm{dq}=$ Esta $\mathrm{d} \% \mathrm{C} 3 \%$ ADsticas + sociales $+\mathrm{de}+$ los + pueblos + ind $\% \mathrm{C}$ $3 \%$ ADgenas + en + Chile,+ Censo $+2002 \& h l=$ pt-BR\&s $\mathrm{a}=$ X\&ved=0ahUKEwi4kKf71dLpAhVWHbkGHS7_ DCwQ6AEIKzAA

MINISTERIO DE PLANIFICACION NACIONAL Y POLITICA ECONOMICA. Instituto Nacional de Estadísticas. 2018. Síntesis de resultados Censo 2017. Disponible en: https://www.censo2017.cl/descargas/ home/sintesis-de-resultados-censo2017.pdf

MONTORO BALLESTEROS, Alberto. El funcionalismo en el derecho: notas sobre N. Luhmann y G. Jakobs. Anuario de Derechos Humanos. Nueva Época, v. 8, p. 365-374, 2007.

MORITA; LUXARDO, NATALIA (Eds.). El orden cuestionado: lecturas de antropología jurídica. Buenos Aires: UNSAM Edita, 2018b. p. 117-130

NELKEN, David (ed.). Comparing legal cultures. Vermonth: Darmonuth Publishing Company, 1997.

PAILLACURA, Darwin. La cultura jurídica chilena frente al derecho fundamental a la identidad cultural de los pueblos indígenas: un análisis del campo jurídico de la Araucanía. Tesis (Ciencias Jurídicas) - Universidad Católica de Temuco, 2019.

PÁSARA, Luis (ed.). Los actores de la justicia Latinoamericana. Salamanca: Universidad de Salamanca, 2007.

PIZZOLO, Calogero. Comunidad de intérpretes finales: relación entre tribunales supranacionales, constitucionales y supremos: el diálogo judicial. Buenos Aires: ASTREA, 2017.

POU, Francisca. Justicia constitucional y protección de derechos en América Latina: el debate sobre la regionalización del activismo. En: RODRÍGUEZ, Cesar (ed.). El derecho en América Latina: un mapa para el pensa- 
miento jurídico del siglo XXI. Buenos Aires: Siglo XXI, 2011. p. 231-250.

RAMÍREZ, Silvina. Siete problemas del Nuevo Constitucionalismo indígena. En: YRIGOREN, Raquel. (ed.). Pueblos Indígenas: constituciones y reformas políticas en América Latina. Lima: ILSA, INESC, IIDS, 2010.

RODRÍGUEZ, César. Navegando la globalización: un mapamundi para el estudio y la práctica del derecho en América Latina. In: RODRÍGUEZ, CÉSAR (Coord.) El derecho en América Latina: un mapa para el pensamiento jurídico del siglo XXI. Buenos Aires: Siglo XXI, 2011.

SARMENTO, Daniel. Direitos fundamentais e relações privadas. 2. ed. Rio de Janeiro: Editora Lumen Juris, 2010

SANTOS, Boaventura de Sousa. Toward a new common sense: law, science and politics in the paradigmatic transition. New York: Routledge, 1995.

SIEDER, Rachel. Pueblos indígenas y derecho (s) en América Latina. In: RODRÍGUEZ, CÉSAR (ed). El derecho en América Latina: un mapa para el pensamiento jurídico del siglo XXI. Buenos Aires: Siglo XXI, p. 302-321.

SIEMS, Mathias. Comparative Law (Law in context). 2. ed. Cambridge: Cambridge University Press, 2018.

SILVEIRA SIQUEIRA, Gustavo. Movimentos sociais e cultura jurídica brasileira. Revista Direitos Culturais, v. 5, n. 8, 2010.

SOUSA, Mariana. Breve panorama de la reforma judicial en América Latina: objetivos, desafíos y resultados. En: LORA, Eduardo (ed.) El estado de las reformas del Estado en América Latina. Bogotá: Banco Mundial del Desarrollo, 2007. p. 99-137.

SOUZA NETO, Cláudio Pereira de; SARMENTO; Daniel. Direito constitucional: teoria história e métodos de trabalho. 2. ed. Belo Horizonte: Fórum, 2014.

SQUELLA, Agustín. La cultura jurídica chilena. Santiago de Chile: Corporación de promoción universitaria, 1988.

SQUELLA, Agustín. Filosofía del Derecho. Santiago de Chile: Editorial Jurídica de Chile, 2001.

TARELLO, G. Cultura giuridica e politica del diritto, II Mulino. Bologna: [S.n], 1988. p. 24
TATE, C. Neal; VALLINDER, Torbjorn. The global expansion of judicial power. New York: New York University Press, 1995.

TRIBUNAL CONSTITUCIONAL ALEMÁN. BVerfGE 7, "Caso Lüth”, 198, 1958.

CHILE. Tribunal Constitucional. Rol 2552-2013, 24 diciembre 2015.

CHILE. Tribunal Constitucional. Rol 2387-2012, 23 enero 2013.

VARELLA, Marcelo. Internacionalização do direito: direito internacional, globalização e complexidade. Tese (Doutorando em Direito Internacional) - Faculdade de Direito, Universidade de São Paulo (USP), São Paulo, 2012.

VERDUM, Ricardo. La estrategia conservadora y neoliberal contra los derechos de los pueblos indígenas y comunidades tradicionales en Brasil. Debates indígenas, nov. 2019, p. 3-4, 2019. Disponible en: https://www. researchgate.net/publication/337810907_La_estrategia_conservadora_y_neoliberal_contra_los_pueblos_ indigenas_en_Brasil_2016-2019

WEBER, Max. Economía y sociedad. México: Fondo de Cultura Económica, 2014.

WINCKLER, Silvana Terezinha; CANZI, Idir; BRAUN, Helenice da Aparecida Dambrós. Direitos humanos e multietnicidade como desafios à Cultura jurídica brasileira. Revista Direitos Culturais, v.6. n. 11, 2011.

YRIGOYEN, Raquel, El horizonte del constitucionalismo pluralista: del multiculturalismo a la descolonización. En, RODRÍGUEZ, C. (coord.). El derecho en América Latina: un mapa para el pensamiento jurídico del siglo XXI. Buenos Aires: Siglo XXI, 2011. p. 139159.

YRIGOYEN, Raquel. Pluralismo jurídico y jurisdicción indígena en el horizonte del constitucionalismo pluralista. En: AHRENS, Helen (ed.). El Estado de derecho hoy en América Latina: libro homenaje a Horst Schönbohm. Montevideo: Editorial Konrad-AdenauerStiftung E.V., 2012. p. 171-194. 
Para publicar na Revista de Direito Internacional, acesse o endereço eletrônico www.rdi.uniceub.br ou www.brazilianjournal.org.

Observe as normas de publicação, para facilitar e agilizar o trabalho de edição. 